\title{
A Comparison of Low-Pressure and Supercharged Operation of Polymer Electrolyte Membrane Fuel Cell Systems for Aircraft Applications
}

\author{
Werner, C. ${ }^{\text {a**}}$; Preiß, G. ${ }^{a^{*}}$; Gores, F. ${ }^{\text {a; }}$ Griebenow, M. ; Heitmann, S. ${ }^{\text {b }}$ \\ ${ }^{a}$ German Aerospace Center, Institute of Engineering Thermodynamics, \\ Hein-Saß-Weg 38, 21129 Hamburg, Germany \\ ${ }^{\mathrm{b}}$ Hamburg University, Lothar Collatz Center for Computing in Science, \\ Bundesstraße 55, 20146 Hamburg, Germany
}

\begin{abstract}
Multifunctional fuel cell systems are competitive solutions aboard future generations of civil aircraft concerning energy consumption, environmental issues, and safety reasons. The present study compares low-pressure and supercharged operation of polymer electrolyte membrane fuel cells with respect to performance and efficiency criteria. This is motivated by the challenge of pressure-dependent fuel cell operation aboard aircraft with cabin pressure varying with operating altitude. Experimental investigations of low-pressure fuel cell operation use model-based design of experiments and are complemented by numerical investigations concerning supercharged fuel cell operation. It is demonstrated that a lowpressure operation is feasible with the fuel cell device under test, but that its range of stable operation changes between both operating modes. Including an external compressor, it can be shown that the power demand for supercharging the fuel cell is about the same as the loss in power output of the fuel cell due to low-pressure operation. Furthermore, the supercharged fuel cell operation appears to be more sensitive with respect to variations in the considered independent operating parameters load requirement, cathode stoichiometric ratio, and cooling temperature. The results indicate that a pressure-dependent selfhumidification control might be able to exploit the potential of low-pressure fuel cell operation for aircraft applications to the best advantage.
\end{abstract}

Keywords: multifunctional fuel cell system, polymer electrolyte membrane fuel cell, operating pressure, balance of plant, system efficiency, aircraft auxiliary power.

${ }^{1}$ Corresponding author: Claudia.Werner@DLR.de; +49 (0) 711/6862-8248.

* These authors contributed equally to this work.

\section{Introduction}

Multifunctional system integration of polymer electrolyte membrane fuel cells (PEMFC) offers the potential to completely replace gas-turbine powered auxiliary power units (APU), on-board inert gas generation systems (OBIGGS) and other aircraft subsystems [1, 2]. To make use of this potential both the operating and state conditions of PEMFC, influencing their dynamical behavior and degradation process, respectively, need to be optimized with respect to the environmental conditions aboard civil aircraft [3].

Operating pressure is one of those conditions demanding special attention. From a fuel cell point of view the electrochemical cell potential is directly proportional to the natural logarithm of pressure ratio. Hence, fuel cell power output benefits from increasing the operating pressure (cp. Figure 1). However, pressurizing reactant gases requires more power for auxiliary equipment, for instance, an external compressor. Furthermore, pressurized reactant gases involve additional stress for fuel cell components and affect the water management of PEMFC [4]. From an aircraft point of view a highly alternating pressure ratio exists between inside and outside an aircraft due to independent decrease of external pressure and conditions within the pressurized cabin, both related to the flight altitude (cp. Figure 2). Since the pressure dependencies of fuel cells as well as the pressure curve for aircraft 
operation show non-linear behavior, an analysis is necessary to identify the most efficient PEMFC operating points for aircraft applications.

In the present study, the low-pressure operation of PEMFC driven by characteristic pressure ratios of aircraft flight conditions and supercharged PEMFC operation using an electrically operated compressor are compared with respect to operating ranges, output power and system efficiency with respect to aircraft operation.

Within this study, an experimental investigation is performed to verify feasibility and stability of lowpressure PEMFC operation in suction mode. The corresponding test plan uses an underlying (modelbased) design of the experiment. The experimental results are used to validate numerical studies visualizing gross and net efficiencies of lowpressure and supercharged PEMFC operation, respectively. Experimental and numerical results of both PEMFC operating modes are compared to each other and evaluated with respect to performance and efficiency criteria. Furthermore, a sensitivity analysis of low-pressure as well as supercharged PEMFC operation is performed with respect to variations in operating parameters. Finally, a summary of the results is provided along with an outlook for further investigations. Besides pressure, the operating parameters cooling temperature, cathode stoichiometric ratio and load requirement are varied during experiments.

\section{Experimental Investigation of Low-Pressure PEMFC Operation}

In this section the PEMFC device under test is introduced and the test facility for low-pressure PEMFC operation in suction mode is illustrated.

The PEMFC device under test is an air-breathing hydrogen fuel cell of HyPM-XR 12 type manufactured by Hydrogenics Corporation (cp. Figure 3). This fuel cell power module integrates fuel cell stack, electronic control system, coolant pump, (cathode) pressure regulator, anode recirculation pump, and solenoid valves. Besides integrating this peripheral equipment, Hydrogenics' HyPM-XR series is characterized by quick-start, self-humidifying as well as low-pressure capabilities [5]. The basic specifications of a HyPM-XR 12 are summarized in Table 1.
A test facility was developed and assembled at the Hamburg site of the Institute of Engineering Thermodynamics (TT) at the German Aerospace Center (DLR) to investigate the low-pressure operation of PEMFC systems through suction mode (cp. Figure 4). This test facility is able to provide a volume flow up to $150 \mathrm{~m}^{3} / \mathrm{h}$ on the cathode side and up to $1.5 \mathrm{~m}^{3} / \mathrm{h}$ on the anode side of the fuel cell, respectively; while the absolute operating pressure is adjustable on the cathode side between $200 \mathrm{mbar}$ and $1000 \mathrm{mbar}$ (the pressure on the anode side of the PEMFC device under test is adapted via a pilot line). In general, about $30 \mathrm{~kW}$ of thermal power and $25 \mathrm{~kW}$ of electric power can be drawn from the test facility, whereas the fuel cell operating temperature is adjustable between $10^{\circ} \mathrm{C}$ and $70^{\circ} \mathrm{C}$.

Within the test facility, two vacuum pumps provide the necessary pressure level for suction operation at ambient pressure $p=p_{\text {ambient }}$ as well as lowpressure $p<p_{\text {ambient }}$. A pneumatically controlled valve at the stack inlet adjusts the cathode air mass flow for fuel cell operation. At the stack outlet, a liquid-cooled condenser (plate heat exchanger) and a cyclone separator collect the water generated inside the fuel cell. Water drain from the system against low-pressure is realized by separate condensate pumps. The pressure level at the inlet of the fuel cell stack is used as a reference to regulate the proportional valve at the system outlet. Lowpressure on the cathode line is provided by a vacuum claw compressor with a high volume rate. The pressure of hydrogen at the stack inlet is regulated equal to the cathode inlet. This is realized by a mechanical pressure regulator. In order to refer the pressures to each other the spaces of anode and cathode are communicating with the pressure dome of the pressure regulator via pilot line. The system is driven in recirculation mode, but for purging impurities and water, a solenoid valve at the outlet of the fuel cell stack opens in load dependent periodic intervals for 0.5 seconds. A low-pressure generator located downstream of the anode outlet of the fuel cell provides the driving pressure difference, which is set to about 200 mbar below the stack pressure. This is realized by a mechanical upstream pressure regulator, which is also equipped with a pilot line communicating with the cathode pressure as well. The vacuum compressor and the subsequent sensors have to be protected from high moisture loads. Therefore a liquid-cooled condenser 
dries the gas stream from the fuel cell when entering the low pressure generating unit. The unregulated vacuum downstream of the pressure regulator is provided by an oil sealed rotary-vane pump.

Furthermore, the test facility includes an appropriate gas supply, cooling system, electronic load, measurement instrumentation as well as a control and data collection system, described below:

Hydrogen is fed into the system by the central laboratory supply at $5 \mathrm{bar}$. The air used for operation is taken from the laboratory environment. For safety and flexibility reasons the applied generation of low-pressure on the anode and cathode lines is separated, so the gas flows are strictly divided over the whole process. The pressure difference over the membranes is kept small by a mechanical communicating vacuum control system. The fuel cell cooling lines are connected to the laboratory cooling system via plate heat exchangers. In order to ensure a constant fuel cell temperature, a mixing valve in the primary cooling circuit is regulating the heat transfer. An additional cold water aggregate is used to draw heat from the thermic condensers on the anode and cathode sides at low temperatures. The generated electric power is controlled by an electronic load which feeds the current into the grid. The load can be cut off from the system immediately by opening high current contactors. This ensures a quick shutdown in case of system failures to prevent damages to the fuel cell. In order to record the relevant input, output and environmental variables during the experiments, the test facility is equipped with 80 sensors registering pressures, temperatures, gas concentrations, relative humidity, mass flows, currents and voltages. On the cathode side temperature and pressure are measured at stack inlet, outlet and downstream the condenser. In addition, mass flow, relative humidity and oxygen concentration are determined at stack inlet and after condensation. Further, the system exhaust air is analyzed for amounts of hydrogen. On the anode side the hydrogen mass flow at system inlet is measured. Furthermore, hydrogen concentration and relative humidity are ascertained downstream of the condenser at the stack outlet. A pressure sensor and an overpressure switch are installed at the anode inlet; further, pressures are recorded at the purge valve as well as inside the controlled lowpressure and the vacuum part, respectively. The mass flow of the coolant as well as the input and output temperatures at the plate heat exchangers are measured to monitor cooling and condensation. The sensor signals are fed into an A/D converter system and then transferred to a data logger via CAN-Bus protocol. The recorded and scaled data are transferred via Ethernet to the data storage of a PC. The system controls are programmed in MATLAB/Simulink [6] and an industrial real time PC is used to execute the control model. The human machine interface is programmed in Simulink as well and is located on a separate desktop PC, where all facility controls are implemented and all relevant operating parameters of the fuel cell, the auxiliary devices and the low-pressure generators are displayed in online-graphs.

Except for the operating pressure level, a continuous variation of the fuel cell operating parameters load requirement (electric current), cathode stoichiometric ratio, and cooling temperature is possible at the test facility. Furthermore, its modular design provides possibilities for extensions or variations to characterize the operation of PEMFC and subcomponents, e.g. condensers, dryers or power electronics.

It needs to be noted that, due to experimental constraints, we make the following assumptions:

1. Because of a specific minimal flow resistance of the PEMFC device under test, the operating pressure on the cathode side of Hydrogenics' HyPM-XR 12 is adjustable up to $p=$ 950 mbar at the test facility. Therefore, within the present study ambient pressure is set to $p_{\text {ambient }}=950 \mathrm{mbar}$.

2. The cooling temperature, the temperature of the cooling fluid, is recorded at the outlet of the cooling fluid at the PEMFC device under test. Since all experimental runs show stationary behavior, the operating temperature of the PEMFC is equated with the cooling temperature within the present study.

\section{Numerical Study}

This section explains the model-based design of the experiment for low-pressure PEMFC operation (cp. Section 3.1) as well as the phenomenological 
mathematical modeling of low-pressure and supercharged PEMFC operation in Section 3.2 and Section 3.3, respectively.

\subsection{Design of the Experiment}

Based on the specification of the Hydrogenics HyPM-XR 12 fuel cell module under test and the operational requirements motivated by prospective aircraft applications, interval and step size of each PEMFC operating parameter were defined with respect to experimental investigation as shown in Table 2.

A full-factorial (complete) design of the experiment encapsulates all possibilities of input parameter configurations; in the present experimental investigation such a design amounts to $5^{4}=625$ different parameter configurations (four different operating parameters each varied over five values). Since such a number of individual experimental runs causes high expenditure of time, expense of process gases as well as a degradation of the PEMFC device under test, one design aim of the experiment is to reduce the number of necessary experimental runs without losing sufficient evidence of scientific interrelation [7].

The purpose of so-called $D$-optimal design of experiment is to find the optimal set of experimental runs (design matrix) from a candidate set of experimental runs with given model specifications and the amount of permitted experimental runs. This candidate set consists of all the admissible points of the experimental region. In order to find the optimal set of experimental runs the $D$-optimal algorithm maximizes the determinant of the information matrix $J$, given by

$$
J=X^{T} * X,
$$

where $X$ denotes a design matrix. The design matrix of an experiment contains data of independent variables of the experiment. Parameter settings of the independent variables are listed row wise in the design matrix. Accordingly, one row in the design matrix corresponds to one experimental run.

Hence, the " $D$ " in $D$-optimal refers to the determinant of the information matrix $J$. In order to understand why the maximization of this determinant is advantageous, consider the general regression problem

$$
\min \|y-X * \beta\|_{2} \quad \text { with } \beta \in R^{l},
$$

where $X \in R^{k, l}$ is the design matrix, $\beta$ the vector of estimated coefficients, $l$ the number of coefficients, $y \in R^{k}$ the target variable, $\mathrm{m}$ the number of experiments and $\|.\|_{2}$ the Euclidian norm. Minimizing the quadratic error between the target variable y and the model function $X * \beta$ leads to a model function

$$
X * \beta=\beta_{0}+\beta_{1} * X^{1}+\beta_{2} * X^{2}+\cdots .
$$

The optimal estimated parameters $\beta_{j}$ are given by

$$
\beta=\left(X^{T} * X\right)^{-1} * X^{T} * y
$$

with the corresponding covariance matrix

$$
\operatorname{Cov}(\beta)=\frac{\sigma^{2}}{X^{T} * X} \quad \rightarrow \quad s e_{j}=\sqrt{\operatorname{Var}(\beta)} .
$$

The standard deviations $s e_{j}$ of the coefficients $\beta_{j}$ are the square roots of the diagonal elements of the covariance matrix. Smaller standard deviations lead to smaller intervals of confidence around the coefficients and therefore more accurate estimates. Hence, in order to minimize the standard deviations, the (determinant of the) information matrix $J=X^{T} * X$ needs to be maximized.

A way to illustrate the $D$-optimal design is the geometrical approach. The determinant of the information matrix corresponds to the volume that is spanned between the chosen experimental points. In order to illustrate this, consider two variables $X_{1}, X_{2}$ that are investigated at three levels, denoted $-1,0$ and 1 . These amounts to $3^{2}=9$ possible parameter configurations (cp. Figure 5). Furthermore, propose a linear regression model $y=f(x)=\beta_{0}+\beta_{1} * X^{1}+\beta_{2} * X^{2}+e, \quad$ which incorporates three parameters that need to be estimated. Assume further, that it is intended to perform exactly three experimental runs as illustrated in Figure 5 to Figure 8.

For example, choosing out of the 9 possible parameter configurations the 3 specific experimental runs $\left\{X_{1}=-1, X_{2}=0\right\}, \quad\left\{X_{1}=\right.$ $\left.0, X_{2}=-1\right\}$ and $\left\{X_{1}=0, X_{2}=1\right\}$ the design matrix reads

$$
X=\left(\begin{array}{ccc}
1 & 0 & -1 \\
1 & -1 & 0 \\
1 & 0 & 1
\end{array}\right) .
$$


Its transpose and the corresponding information matrix yield

$$
X^{T}=\left(\begin{array}{ccc}
1 & 1 & 1 \\
0 & -1 & 0 \\
-1 & 0 & 1
\end{array}\right)
$$

and

$$
J=X^{T} * X=\left(\begin{array}{ccc}
3 & -1 & 0 \\
-1 & 1 & 0 \\
0 & 0 & 2
\end{array}\right)
$$

respectively. The associated determinant becomes $\operatorname{det}(J)=4$ as shown in Figure 6. This example illustrates how a growing determinant coincides with a larger volume that is spanned by the chosen specific experimental runs over the whole candidate set. Furthermore, it can be observed in the example that any 3 corner points as specific experimental runs lead to a maximal determinant of 16 for the corresponding information matrix and provide the most precise fitting parameters for an underlying mathematical model (cp. Figure 8). Furthermore, this shows that a $D$-optimal design plan is not necessarily unique [7].

The main advantage of the $D$-optimal design is that the available information is used in the most efficient way possible for the underlying model. Another advantage is the flexibility of this approach, as the input variable levels can be chosen freely. It is also possible to choose different amounts of levels for each input variable. Furthermore, the number of conducted experiments can also be chosen freely, except a minimum amount that results from the amount of parameters present in the underlying model. Apart from that it is possible to incorporate older experimental runs into a new design. If, for example, in the course of the experiments it turns out that steady operation at certain points of the candidate matrix cannot be realized, a new experimental design can be created based on a reduced candidate matrix, in which the infeasible points are not included. The algorithm then takes the experimental runs that are already completed and incorporates them into the optimization procedure to generate a new optimal design. During the optimization procedure it is possible that some experimental points are run several times, because the algorithm identifies these points as especially beneficial for the determinant of the design matrix. Overall, it becomes apparent that steady operation of the PEMFC device under test conditions is possible in 363 measuring points out of the whole candidate set of 625 (full-factorial design).

In MATLAB $D$-optimal algorithm is implemented under the name 'candexch' [6]. It is used during the experimental design in order to create the $D$ optimal experimental matrix, which contains 169 experimental points. These can be split up into three categories: 149 points were calculated by the $D$-optimal algorithm, 17 points were chosen independently, in order to validate the model a posteriori statistically and the remaining 3 points are repeated measurements of the reference point (0-point) of the experiment. The 0 -point is the point, in which all normed variables are set to their respective middle setting $\left(\lambda=2.1 ; t=55^{\circ} \mathrm{C} ; p=\right.$ $775 \mathrm{mbar}$ and $I=132 \mathrm{~A}$ ). It is measured repeatedly in order to recognize potential drift behavior during experimentation.

Due to physical limitations of the low-pressure test facility or the PEMFC itself, some areas of the experimental region do not allow for stable operation. Hence, these areas, which are determined during the experimentation, are excluded from the experimental region. A complete overview of the excluded regions is summarized in [8].

\subsection{Low-Pressure PEMFC Operation}

Complementary to the design of the experiment, the numerical study aims to evaluate the stack performance of the PEMFC device under test in the different operating modes; this section shows the low-pressure operation at first.

The evaluation of low-pressure PEMFC operation is based on stack gross power $P_{\text {stack,gross }}$ and average voltage efficiency $\eta_{U}$ with

(9) $\quad P_{\text {stack,gross }}=\left(I_{\text {grid }}+I_{B O P, \text { internal }}\right) *$ $U_{\text {stack }}(I)$

and

$$
\eta_{U}=\frac{\bar{U}_{c e l l}(I)}{n * U_{0}}
$$

respectively, where $I_{\text {grid }}$ denotes the load from external consumers (e.g. the public grid), $I_{B O P, \text { internal denotes the load from internal }}$ peripheral components (i.e. cooling pump, anode recirculation pump, control electronics and solenoid 
valves), $U_{\text {stack }}$ denotes the total stack voltage, $\bar{U}_{\text {cell }}$ denotes the average cell voltage and $U_{0}$ denotes the reversible fuel cell potential [3].

A phenomenological mathematical model based on the polynomial model function (3) determined by $D$-optimal design of experiment for low-pressure PEMFC operation is used. Hence, for the electrochemical potential of the fuel cell the relation studied has the form

(11) $f(X, p)=a_{0}+a_{1} * X+a_{2} * p+a_{3} * X *$ $p+a_{4} * X^{2}+a_{5} * p^{2}$,

where $p$ denotes the operating pressure and $X$ denotes the design matrix concerned with a triple $(I, \lambda, t)$ of operating parameters. The optimal numerical values for coefficients $a_{1}, \ldots, a_{5}$ in equation (9) are determined by linear regression with respect to the associated experimental data and are summarized in Table 3.

\subsection{Supercharged PEMFC Operation}

The principal configuration for supercharged PEMFC operation is illustrated in Figure 9.

A compressor suitable for supercharging the PEMFC device under test in its respective feasible operation range was selected; that is the lateral compressor with frequency converter model number 2BH7610-0AH16-8 by Gardner Denver Inc. [9]. Figure 10 shows the characteristic maps of this type of compressor according to data sheets and measurements data communicated by Gardner Denver GmbH; measurement data have been fitted by a least-squares method and linear interpolation was used to determine interim values.

The evaluation of supercharged PEMFC operation reflects the balance of the fuel cell stack as well as the balance of the external compressor unit. Evaluation criteria are system net power $P_{\text {system,net }}$ and total system efficiency $\eta_{\text {system }}$ with

$$
P_{\text {system,net }}=P_{\text {stack,gross }}-P_{B O P, \text { external }}
$$

and

$$
\eta_{\text {system }}=\eta_{U} * \eta_{B O P, \text { external }}
$$

with

$$
\eta_{B O P, \text { external }}=\frac{P_{\text {stack,gross }}-P_{B O P, \text { external }}}{P_{\text {stack,gross }}},
$$

respectively, where $P_{B O P \text {,external }}$ denotes the power demand of external compressor in the corresponding operating point (cp. Figure 10).

Again, a phenomenological mathematical model based on equation (11) determined by $D$-optimal design of experiment is used for supercharged PEMFC operation. This time the optimal numerical values for coefficients $a_{1}, \ldots, a_{5}$ in equation (11) result to those shown in Table 4.

In addition to the constraints assumed for the criteria to evaluate the low-pressure operation, the supercharged PEMFC operation assumes the following:

1. The load-dependent pressure drop between cathode inlet and outlet of the PEMFC is neglected; this would actually require a higher compressor load to compensate the low-pressure environment at cathode outlet.

2. The temperature increase of the cathode inlet air due to compression is neglected; this would actually result in a higher parasitic loss due to an increased cooling demand.

\section{Results and Conclusion}

This section summarizes and compares the results of both low-pressure (cp. Section 4.1) and supercharged PEMFC operation (cp. Section 4.2), and provides a sensitivity analysis of the results in Section 4.3.

\subsection{Results of Low-Pressure PEMFC Operation}

In this section, the results of low-pressure PEMFC operation are presented, considering the variation of operating pressure/load requirement (electric current), operating pressure/cathode stoichiometric ratio, and operating pressure/cooling temperature.

The following results are based on a local-quadratic model function, which means a different quadratic model function exists for each partial (twodimensional) surface spanned by two operating parameters in the complete (four-dimensional) space of experimental runs (each with the other two operating parameters fixed). These quadratic model functions solely depend on the measuring points depicted in each case; they are illustrated in Figure 11 to Figure 16 leading to numerical regression 
coefficients summarized in Table 3. Hence, there exists a unique regression function per individual partial experimental surface. Therefore, the following statements with respect to the connection between operating parameters and dependent variables are only valid in the partial experimental regions. There also exists a higher order polynomial complete model, which is statistically verified and spans over the whole space of admissible experimental runs. This model yields similar results as the model used in this article [10].

Figure 11 to Figure 16 include two fixed operating parameters as well as two varied operating parameters each. While the operating pressure $p$ is varied in each case, the second operating variables are varied on the abscissa, respectively. Each case involves measuring points (MP) as well as regression functions (RF).

Experimental data and associated regression functions for stack gross power $P_{\text {stack,gross }}$ and average voltage efficiency $\eta_{U}$ under varying load requirement during low-pressure PEMFC operation are illustrated in Figure 11 and Figure 12. In both cases the corresponding cathode stoichiometric ratio and cooling temperature take fixed values at $\lambda=2.1$ and $t=45^{\circ} \mathrm{C}$, respectively. As depicted in Figure 11 and Figure 12, the low-pressure operation of the PEMFC device under test is stable in the complete range of load variation ( $I=50-$ $300 \mathrm{~A}$ ) without any constraints for operating pressure between $p=700$ mbar and $p=$ 950 mbar.

Absolute values of stack gross power $P_{\text {stack,gross }}$ in Figure 11 increase with increasing load requirement $I$, as expected (cp. Equation (9)). The indicated difference in $P_{\text {stack,gross }}$ for operating pressures $p=700$ mbar and $p=950$ mbar must be assigned to the drops in reactant partial pressure, in particular to the drop in oxygen partial pressure [3]. The gain in the difference of $P_{\text {stack,gross }}$ between $p=700$ mbar and $p=950$ mbar with increasing load requirement $I$ could be explained by the presence of liquid water inside the PEMFC. Since liquid water inside a PEMFC limits the transport of reactant gases through the pore structures of gas diffusion as well as electrocatalyst layers, the cell potential decreases. Although all of the respective experimental runs in Figure 11 are rated a fuel cell humidification status 'flooded' [8], it is supposed that the higher operating pressure $p=950 \mathrm{mbar}$ better counteracts the mass transport losses with increasing load requirement. This indicates that the self-humidification of the PEMFC device under test reaches optimal values for membrane water content even at $p=p_{\text {ambient }}$ only for optimal operating temperatures. Furthermore, this suggests that the self-humidification control is load-dependent but not pressure-dependent.

Figure 12 shows the average voltage efficiency $\eta_{U}$ decreasing with increasing load requirement $I$, as expected (cp. Equation (10)). For $\eta_{U}$, like with $P_{\text {stack,gross }}$, the regression function for operating pressure $p=950$ mbar is above the regression function for $p=700$ mbar in the complete range of load variation $(I=50-300 A)$. This results from the drops in reactant partial pressure, in particular to the drop in oxygen partial pressure, too [3]. The gain in the difference of $\eta_{U}$ between operating pressures $p=700 \mathrm{mbar}$ and $p=$ 950 mbar with increasing load requirement $I$ again indicates the presence of liquid water inside the PEMFC at operating pressures $p<p_{\text {ambient }}$ (ср. above).

Figure 13 and Figure 14 illustrate experimental data and associated regression functions for stack gross power $P_{\text {stack,gross }}$ and average voltage efficiency $\eta_{U}$ under varying cathode stoichiometric ratio during low-pressure PEMFC operation. The load requirement and the cooling temperature are fixed operating parameters at values $I=300 \mathrm{~A}$ and $t=45^{\circ} \mathrm{C}$, respectively. It should be noted that the restricted regression functions in Figure 13 and Figure 14 indicating operation around $p=$ $700 \mathrm{mbar}$ are not due to stability issues of the lowpressure PEMFC operation itself. This limitation is due to the involved vacuum pump which is not able to provide sufficient low-pressure volume flow on the cathode line of the test facility for cathode stoichiometric ratios $\lambda>2.1$ (cp. Figure 4).

The regression function of stack gross power $P_{\text {stack,gross }}$ for operating pressure $p=700 \mathrm{mbar}$ is below the regression function of $P_{\text {stack,gross }}$ at $p=950 \mathrm{mbar}$ in Figure 13. This characteristic must be assigned to the drops in reactant partial pressure, especially to the drop in oxygen partial pressure, as well [3]. Nevertheless, both regression functions do not show a direct dependence of cathode stoichiometric ratio in the respective range 
of variation $(1.7<\lambda<2.5$ at $p=950 \mathrm{mbar}$ and $1.7<\lambda<2.1$ at $p=700 \mathrm{mbar}$, respectively). Hence, the difference of $P_{\text {stack,gross }}$ between $p=700 \mathrm{mbar}$ and $p=950 \mathrm{mbar}$ remains constant with respect to measurement accuracy. Therefore, a stable and reliable power output of the PEMFC device under test is suggested when cathode stoichiometric ratio $\lambda$ is varied between 1.7 and 2.5 or between 1.7 and 2.1 , respecticely, at load requirement and cooling temperature of $I=300 \mathrm{~A}$ and $t=45^{\circ} \mathrm{C}$, respectively.

The average voltage efficiency $\eta_{U}$ in Figure 14 shows a behavior comparable with corresponding $P_{\text {stack,gross: }}$ the regression function of $\eta_{U}$ for operating pressure $p=700 \mathrm{mbar}$ is clearly below the regression function of $\eta_{U}$ at $p=950 \mathrm{mbar}$. The relevant drops in reactant partial pressure, especially the drop in oxygen partial pressure are again the reason for this characteristic [3]. However, a stable and reliable degree of efficiency of the PEMFC device under test is achieved when cathode stoichiometric ratio $\lambda$ is varied between 1.7 and 2.5 or between 1.7 and 2.1, respecticely, at load requirement and cooling temperature of $I=300 \mathrm{~A}$ and $t=45^{\circ} \mathrm{C}$, respectively.

Regression functions and underlying experimental data with respect to varying cooling temperature during low-pressure PEMFC operation are presented in Figure 15 and Figure 16. Fixed operating parameters in this case are load requirement and cathode stoichiometric ratio at values $I=300 A$ and $\lambda=2.1$, respectively. This time the observed restriction of regression functions in Figure 15 and Figure 16 indicating operation at $p=700$ mbar are due to stability issues of the low-pressure operation of the PEMFC device under test itself. The restriction in the regression functions can be verified by the lack of feasible experimental runs for operating temperatures $t>55^{\circ} \mathrm{C}$ and operating pressures $p<900 \mathrm{mbar}$ in Figure 15 and Figure 16. As the reason for the restricted operating temperature range at low-pressure PEMFC operation an insufficient humidification is suggested, since the humidification state of the PEMFC device under test was rated ' $d r y$ ' already at operating temperature $t=55^{\circ} \mathrm{C}$ for operating pressures $p=700 \mathrm{mbar}$ and $p=750 \mathrm{mbar}$ [8].

The stack gross power $P_{\text {stack,gross }}$ of low-pressure PEMFC operation under varying cooling temperature in Figure 15 shows the expected characteristic: $P_{\text {stack,gross }}$ increases with increasing operating temperature up to an optimal (thermal) operating point; with operating temperatures above this optimal operating point $P_{\text {stack,gross }}$ decreases again. These optimal operating points are at cooling temperatures about $t=49{ }^{\circ} \mathrm{C}$ and $t=53^{\circ} \mathrm{C}$ for operating pressures $p=700 \mathrm{mbar}$ and $p=$ 950 mbar, respectively. This characteristic is caused by a linear increase of reversible fuel cell voltage with increasing operating temperature which is overtaken by a nonlinear increase of different voltage losses (e.g. activation and concentration losses) at each specific optimal operating point [3]. The positioning of the regression function for operating pressure $p=$ 700 mbar below the one for operating pressures $p=950$ mbar is caused by the drops in reactant partial pressure, especially to the drop in oxygen partial pressure, as well [3].

Figure 16 confirms the characteristic dependency of low-pressure PEMFC operation with respect to varying cooling temperature by an equivalent behavior of the corresponding average voltage efficiency $\eta_{U}$. Optimal operating points remain at cooling temperatures about $t=49^{\circ} \mathrm{C}$ and $t=$ $53^{\circ} \mathrm{C}$ for operating pressures $p=700 \mathrm{mbar}$ and $p=950$ mbar, respectively (cp. Equation (10)).

\subsection{Results of Supercharged PEMFC Operation}

The results of supercharged PEMFC operation are shown in this section under varying operating pressure/load requirement (electric current), pressure/cooling temperature, and operating pressure/cathode stoichiometric ratio.

These results are based on a local-quadratic model function, too. The quadratic model functions, however, depend on the measuring points depicted in each case including the parasitic losses due to powering the external compressor (cp. Table 5 to Table 7) which lead to different numerical regression coefficients listed in Table 4. Again, there exists a unique regression function per individual partial experimental surface and the following statements with respect to the connection between operating parameters and dependent variables are only valid in the partial experimental regions. 
Figure 17 to Figure 22 include two fixed operating parameters as well as two varied operating parameters each. While the operating pressure $p$ is varied in each case, the second operating variables are varied on the abscissa, respectively. Each case involves measuring points (MP) as well as regression functions (RF).

Experimental data and associated regression functions under varying load requirement during supercharged PEMFC operation are illustrated in Figure 17 and Figure 18. In both cases the corresponding cathode stoichiometric ratio and cooling temperature take fixed values at $\lambda=2.1$ and $t=45^{\circ} \mathrm{C}$, respectively. The associated values for power demand of the external compressor in underlying experimental runs are summarized in Table 5. As expected, the supercharged operation of the PEMFC device under test is stable in the complete range of load variation $(I=50-300 A)$ without constraints (cp. Section 4.1).

Comparing Figure 17 and Figure 11 shows that the regression functions for operating pressure $p=$ $700 \mathrm{mbar}$ in each case are almost identical. Since the power demand $P_{B O P \text {,external }}$ of the external compressor equals 0 for $p=700$ mbar during supercharged PEMFC operation (cp. Equation (12)), the only differences are due to varying numerical regression coefficients (cp. Table 3 and Table 4). As depicted in Figure 17, supercharging the PEMFC device under test requires about the same amount of electric power for the selected external compressor compared to the decrease of $P_{\text {stack,gross }}$ in low-pressure PEMFC operation. Hence, the regression functions for $P_{\text {system,net }}$ in Figure 17 show similar behavior for operating pressures $p=700$ mbar and $p=950$ mbar.

The average voltage efficiency $\eta_{\text {system }}$ of supercharged PEMFC operation at operating pressure $p=950 \mathrm{mbar}$ under varying load requirement in Figure 18 is subject to a vertical replacement when compared to the appropriate regression function of $\eta_{U}$ in Figure 12. This is due to almost linear behavior of the chosen compressor in the respective load range (cp. Table 5). Hence, the efficiency $\eta_{B O P, \text { external }}$ is almost constant (cp. Equation (14)). The regression function for $\eta_{\text {system }}$ at $p=700$ mbar in Figure 18 is basically identical compared to the appropriate regression function of $\eta_{U}$ in Figure 12. This becomes clear since
$\eta_{B O P, \text { external }} \equiv 1$ (ср. Equation (13)). The small differences are due to different numerical regression coefficients (cp. Table 3 and Table 4).

Figure 19 and Figure 20 illustrate experimental data and associated regression functions under varying cathode stoichiometric ratio during supercharged PEMFC operation with the load requirement and the cooling temperature as the fixed operating parameters at values $I=300 \mathrm{~A}$ and $t=45^{\circ} \mathrm{C}$, respectively. The corresponding values for power demand of the external compressor in underlying experimental runs are summarized in Table 6. It is recalled that the restrictions in the regression functions at operating pressure $p=700$ mbar are based on technical constraints of the involved vacuum pump in the test facility and not due to stability issues of the operation of the PEMFC device under test itself (cp. Section 4.1).

Figure 19 presents an almost identical regression function for system net power $P_{\text {system,net }}$ under varying cathode stoichiometric ratio for operating pressure $p=700$ mbar when compared to the corresponding stack gross power $P_{\text {stack,gross }}$ in Figure 13. Again, this deviation is caused by changed numerical regression coefficients (cp. Table 3 and Table 4). For $p=950$ mbar the regression function of $P_{\text {system,net }}$ Figure 19 tends to decrease linearly with increasing cathode stoichiometric ratio. These characteristic results from the linear behavior of the external compressor whose power demand shows an almost linear dependence of the required volume flow (cp. Figure 10). However, for cathode stoichiometric ratios $1.7<\lambda<2.1$ the regression functions of $P_{\text {system,net }}$ take similar values (cp. Figure 19).

The pressure-dependent total system efficiency $\eta_{\text {system }}$ of supercharged PEMFC operation under varying cathode stoichiometric ratios illustrated in Figure 20 follows the trend of the corresponding $P_{\text {system,net }}$ in Figure 19 as expected (cp. Figure 14).

Regression functions and underlying experimental data of system net power $P_{\text {system,net }}$ and total system efficiency $\eta_{\text {system }}$ under varying cooling temperature during supercharged PEMFC operation are presented in Figure 21 and Figure 22. Fixed operating parameters in this case are load requirement and cathode stoichiometric ratio at values $I=300 A$ and $\lambda=2.1$, respectively. The 
corresponding values for power demand of the external compressor in underlying experimental runs are summarized in Table 7 . Here, it is recalled that the observed restriction of regression functions in Figure 21 and Figure 22 indicating operation at $p=700$ mbar are due to stability issues of the PEMFC operation itself, caused by insufficient humidification (cp. Section 4.1).

The pressure-dependent system net power $P_{\text {system,net }}$ of supercharged PEMFC operation under varying cooling temperatures in Figure 21 shows the expected characteristic: $P_{\text {system,net }}$ at operating pressure $p=700$ mbar has almost identical characteristics, whereas $P_{\text {system,net }}$ at $p=950$ mbar is vertically replaced, both compared to corresponding $P_{\text {stack,gross }}$ in Figure 15. This is caused by changed numerical regression coefficients (cp. Table 3 and Table 4) and an almost linear behavior of the chosen compressor (cp. Table 7 ). Hence, the optimal operating points are still at cooling temperatures about $t=49{ }^{\circ} \mathrm{C}$ and $t=$ $53^{\circ} \mathrm{C}$ for operating pressures $p=700 \mathrm{mbar}$ and $p=950$ mbar, respectively. Most interesting in Figure 21 is the indication that the regression function of $P_{\text {system,net }}$ at $p=700 \mathrm{mbar}$ is above the one of $P_{\text {system,net }}$ at $p=950$ mbar for operating temperatures $t \approx 47^{\circ} \mathrm{C}$ and below.

Figure 22 presents the pressure-dependent total system efficiency $\eta_{\text {system }}$ of supercharged PEMFC operation under varying cooling temperature. The behavior of the regression functions at operating pressures $p=700 \mathrm{mbar}$ and $p=950 \mathrm{mbar}$ follow the trend of $P_{\text {system,net }}$ when Figure 22 is compared to Figure 16. Likewise, for operating temperatures $t \approx 47^{\circ} \mathrm{C}$ and below the total system efficiency $\eta_{\text {system }}$ at $p=700 \mathrm{mbar}$ is higher as $\eta_{\text {system }}$ at $p=950$ mbar.

\subsection{Sensitivity Analysis of PEMFC Operation}

This section provides a sensitivity analysis of performance and efficiency for both low-pressure and supercharged PEMFC operation to determine sensitivities of these observable quantities with respect to operating parameters load requirement, cathode stoichiometric ratio and cooling temperature. The results illustrated in Figure 23 to Figure 26 are related to the experimental reference point (RP) with operating parameters at values $I=300 \mathrm{~A}, \lambda=2.1$ and $t=45^{\circ} \mathrm{C}$.

Figure 23 presents the sensitivity of stack gross power $P_{\text {stack,gross }}$ of low-pressure PEMFC operation under varying operating parameters. It can be seen that there is basically no sensitivity of $P_{\text {stack,gross }}$ with respect to varying cathode stoichiometric ratio $\lambda$. This results from the fact that within the present test range there is no direct dependence of $P_{\text {stack,gross }}$ on $\lambda$, at all (cp. Figure 12). However, $P_{\text {stack,gross }}$ exhibits sensitivities with respect to varying load requirement $I$ and cooling temperature $t$. Both sensitivities are almost linear since the behavior of $I$ and $t$ are almost linear in a range of $2.5 \%$ with respect to RP (cp. Figure 11 and Figure 15). But it should be noted that RP was chosen in a way where both $I$ and $t$ are varied in one direction only.

The sensitivity of average voltage efficiency $\eta_{U}$ of low-pressure PEMFC operation under varying operating parameters in Figure 24 shows similar behavior compared to Figure 23. A notable difference is the reversed sign of sensitivity with respect to load requirement $I$. This is explained by the reversed sign of the gradient in Figure 12 compared to Figure 11.

Figure 25 presents the sensitivity of system net power $P_{\text {system,net }}$ of supercharged PEMFC operation under varying operating parameters. In this case a minor linear sensitivity of $P_{\text {system,net }}$ with respect to varying cathode stoichiometric ratio $\lambda$ can be observed. This reflects the almost linear dependence of power consumption of the selected compressor providing the required intake volume flow (which is proportional to $\lambda$ ) as shown in Figure 10. A sensitivity of $P_{\text {system,net }}$ with respect to varying load requirement $I$ and cooling temperature $t$ is also present. The sensitivity of $P_{\text {system,net }}$ with respect to $I$ presents a similar behavior compared to those of $P_{\text {stack,gross }}$ (cp Figure 23) which is due to the linear behavior of $P_{\text {system,net }}$ and the power demand of the selected compressor in the considered range of parameter variation (cp. Figure 12 and Figure 10). The sensitivity of $P_{\text {system,net }}$ with respect to $\lambda$ shows a more distinct behavior when compared to those of $P_{\text {stack,gross }}$ (cp. Figure 23). This is justified by the relative displacement of the respective 
measurement points in Figure 21. Since the regression function of $P_{\text {system,net }}$ at $p=950 \mathrm{mbar}$ is subject to a vertical replacement to lower values, the trends of both regression functions of $P_{\text {system,net }}$ at $p=700 \mathrm{mbar}$ and $p=950 \mathrm{mbar}$ superpose in the same direction.

The sensitivity of average voltage efficiency $\eta_{\text {system }}$ of supercharged PEMFC operation under varying operating parameters in Figure 26 shows similar behavior compared to Figure 25. Again, sensitivity of $\eta_{\text {system }}$ with respect to load requirement $I$ underlies a change in sign. This is explained by the reversed sign of the gradient in Figure 17 compared to Figure 18 as well.

\section{Summary and Outlook}

In this section the results of the present study are summarized (cp. Section 5.1) and an outlook is given motivating further investigations (cp. Section 5.2).

\subsection{Summary}

The present study compares and analyses lowpressure and supercharged PEMFC operation for aircraft applications with respect to performance and efficiency criteria.

While results of low-pressure PEMFC operation are based upon experimental investigations and modelbased design of experiments (cp. Section 2 and Section 3.1), results of supercharged PEMFC operation use a numerical model and characteristic maps of a suitable compressor (cp. Section 3.3).

The following conclusions are drawn:

1. The Hydrogenics HyPM-XR 12 device under test demonstrates that low-pressure PEMFC operation is technically feasible down to an operating pressure $p=700$ mbar (cp. Section 4.1). This low-pressure operation, however, does show a different range of stable operation when compared to supercharged PEMFC operation; in particular, the low-pressure operation is restricted with respect to its operating temperature due to issues with the self-humidification of Hydrogenics' HyPM-XR 12 (cp. Figure 15 and Figure 21). Since selfhumidification of the PEMFC device under test works without restrictions under varying load requirement $I$ and cathode stoichiometric ratio $\lambda$ (cp. Figure 11, Figure 13, Figure 17, and Figure 19), it is supposed that the control of selfhumidification is load-dependent, to some extent temperature-dependent, but not pressuredependent.

2. Comparing both PEMFC operation modes indicates that the power demand of an external compressor for supercharging Hydrogenics' HyPM-XR 12 might compensate the loss in output power of the PEMFC during lowpressure operation (cp. Figure 17 and Figure 19). In addition, the results illustrated in Figure 21 suggest that there exist operating points within the range of stable operation where lowpressure operation of the PEMFC shows better performance and higher efficiency compared to supercharged operation (cp. Section 4.2). Of course, these conclusions are specific for PEMFC as well as the selected compressor (i.e. Gardner Denver 2BH7610-0AH16-8).

3. In general, the present investigation documents that (model-based) design of experiments is a powerful tool with respect to fuel cell operation and analysis. Expenditure, cost, and time of experiments can be reduced using e.g. $D$ optimal design of experiments. Similarly, stress concerning the degradation process of the PEMFC can be reduced because of reduced operating time (cp. Section 3.1 and Section 4.1). Nevertheless, the present investigation reveals that dependencies concerning independent and dependent variables as well as constraints of the device under test and the test facility itself must be considered carefully (cp. Section 4.2 and Section 4.3).

\subsection{Outlook}

Comparing low-pressure and supercharged PEMFC operation for aircraft applications offers potential for further investigations in different directions, e.g.:

1. The present study considers supercharging the PEMFC up to an operating pressure $p=$ 950 mbar since the PEMFC device under test (i.e. Hydrogenics' HyPM-XR 12) is designed for operating pressure $p=p_{\text {ambient }}$. In further investigations the behavior of the PEMFC device under test at operating pressure $p>$ $p_{\text {ambient }}$ shall be considered for further analyzing its area of stable operation with 
respect to performance and efficiency criteria. In almost the same manner it would be interesting to investigate other PEMFC devices with respect to their feasibility of low-pressure operation, in particular PEMFC devices that are designed for optimal operating pressure $p>p_{\text {ambient }}$ (e.g. Ballard FCveloCity ${ }^{\circledR}$-HD series [11]).

2. Since the present study demonstrates the feasibility of low-pressure PEMFC operation (cp. Section 4), further investigations shall optimize the operation of PEMFC operating pressure $p>p_{\text {ambient }}$. This makes it possible to exploit the area of stable operation of a PEMFC under low-pressure as well as its respective performance and efficiency into the development of operating and (feedback) control strategies. Especially, the advantages and disadvantages of a pressure-dependent selfhumidification control shall be analyzed.

3. In further investigations regarding all kind of fuel cell operation, it might be reasonable to consider (model-based) design of experiment to a deeper level. That is to say, considering the thermal, electrochemical, and process technology related characteristics of the PEMFC device under test in more detail to reduce the number of necessary experimental runs and/or to increase information value of fuel cell investigations.

\section{Acknowledgement}

The authors gratefully acknowledge the support received from the Federal Ministry for Economic Affairs and Energy under aviation research program LuFo. In addition, the authors acknowledge helpful discussions with colleagues, especially Florian Becker and Dr. Lucas Busemeyer.

\section{References}

[1] Keim M, Kallo J, Friedrich KA, Werner C, Saballus M, Gores F. Multifunctional fuel cell system in an aircraft environment: An investigation focusing on fuel tank inerting and water generation. Aerospace Science and Technology 2013;4(4):330-338

[2] Pratt JW, Klebanoff LE, Munoz-Ramos K, Akhil AA, Curgus DB, Schenkmann BL. Proton Exchange Membrane Fuel Cells for Electrical Power Generation On-Board Commercial Airplanes. Sandia Report Series 2011; SAND2011-3119

[3] Barbir F. PEM Fuel Cells: Theory and Practice. $2^{\text {nd }}$ ed. New York: Academic Press, 2011.

[4] Larminie J, Dicks A. Fuel Cell Systems Explained. $2^{\text {nd }}$ ed. West Sussex: John Wiley \& Sons, 2003.

[5] Hydrogenics Corporation. HyPM XR 12 Installation and Operation Manual. Version 1.0. Ontario: Hydrogenics Corp. 2011

[6] The MathWorks MATLAB Manual. http://de.mathworks.com/help/ (30.05.2016)

[7] Eriksson L, Johansson E, Kettaneh-Wold N, Wikström C, Wold S. Design of Experiments: Principles and Applications. $3^{\text {rd }}$ ed. Umetrics, 2008.

[8] Werner C, Gores F, Busemeyer L, Kallo J, Heitmann S, Griebenow M. Characteristics of PEMFC Operation in Ambient and Low Pressure Environment Considering the Fuel Cell Humidification. CEAS Aeronautical Journal 2015;6(2):229-243

[9] Gardner Denver GmbH (Elmo Rietschle). EMail communication with sales manager Northern Germany from 12.05.2015.

[10] Griebenow M. Statistische Auswertung zu Experimenten zu Brennstoffzellen im Unterdruckbetrieb. B.Sc. Thesis, University of Hamburg, Germany 2013.

[11] Ballard FCveloCity ${ }^{\circledR}$-HD: Fuel Cell Power Module for Heavy Duty Motive Applications. http://ballard.com/files/PDF/Bus/FCvelocity HD_Family of Products_Low_Res.pdf (30.05.2016) 


\section{Figures}

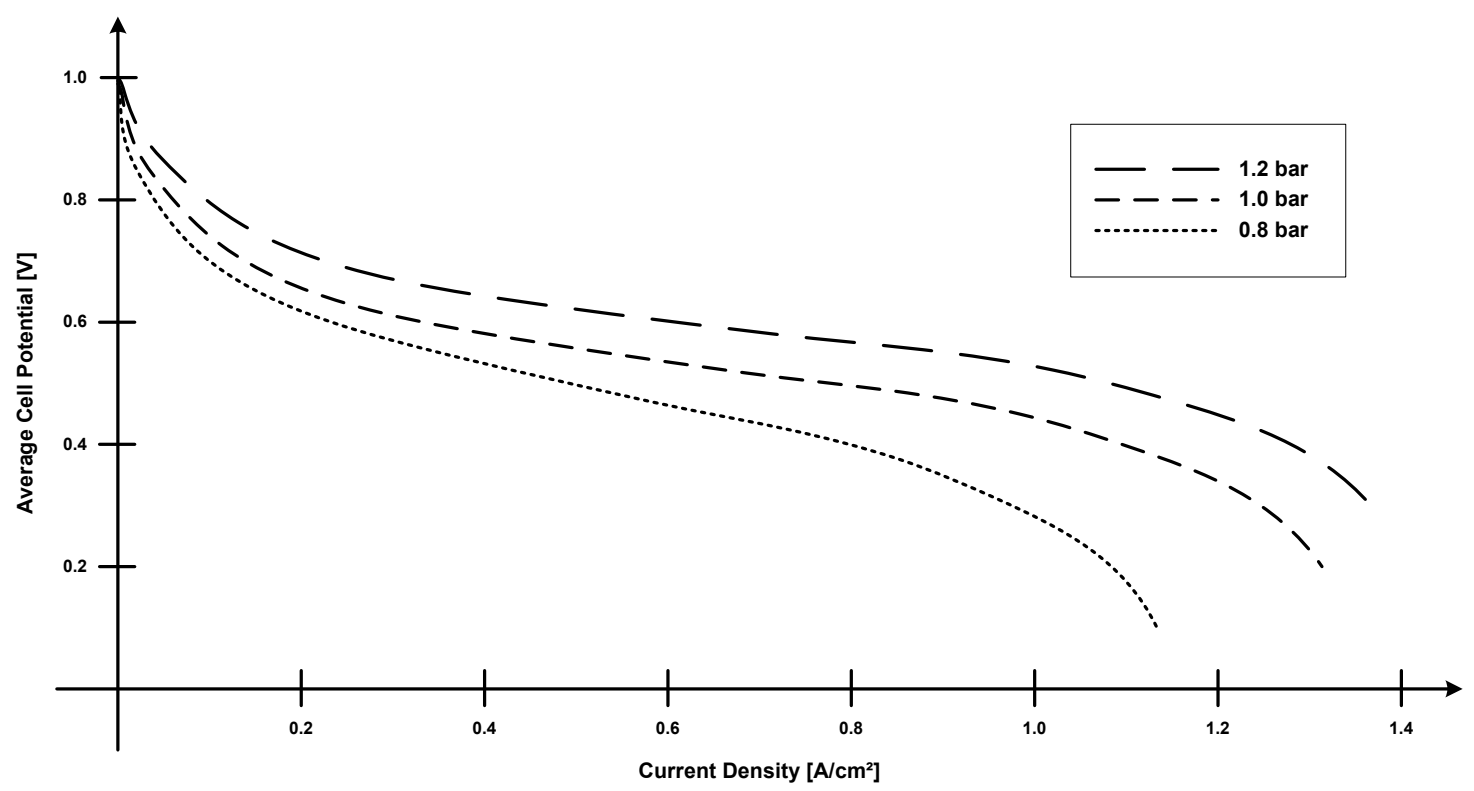

Figure 1: Characteristic electrochemical fuel cell potential at various operating pressures.

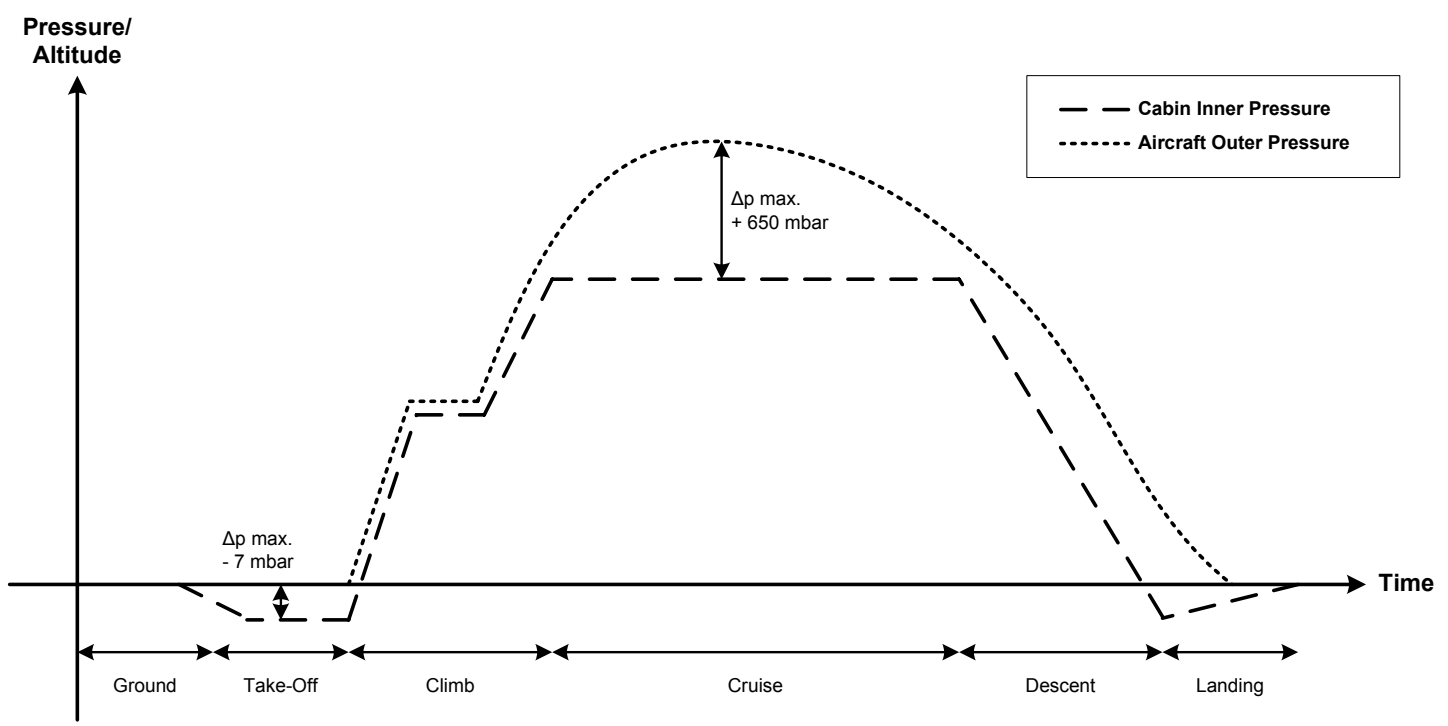

Figure 2: Typical pressurization flight profile of a civil aircraft. 


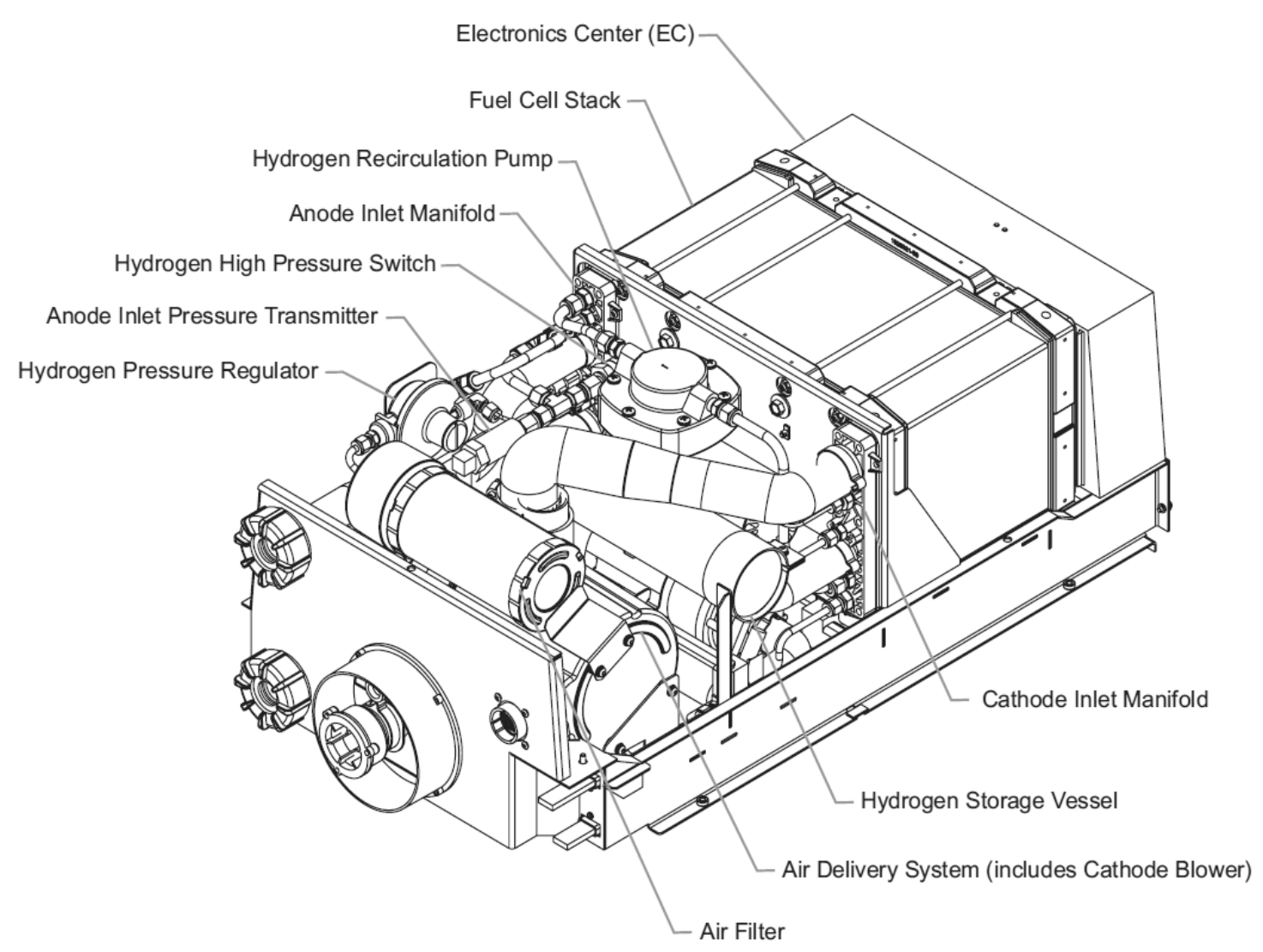

Figure 3: Main components of Hydrogenics' HyPM-XR 12 fuel cell module (top/side view) [5].

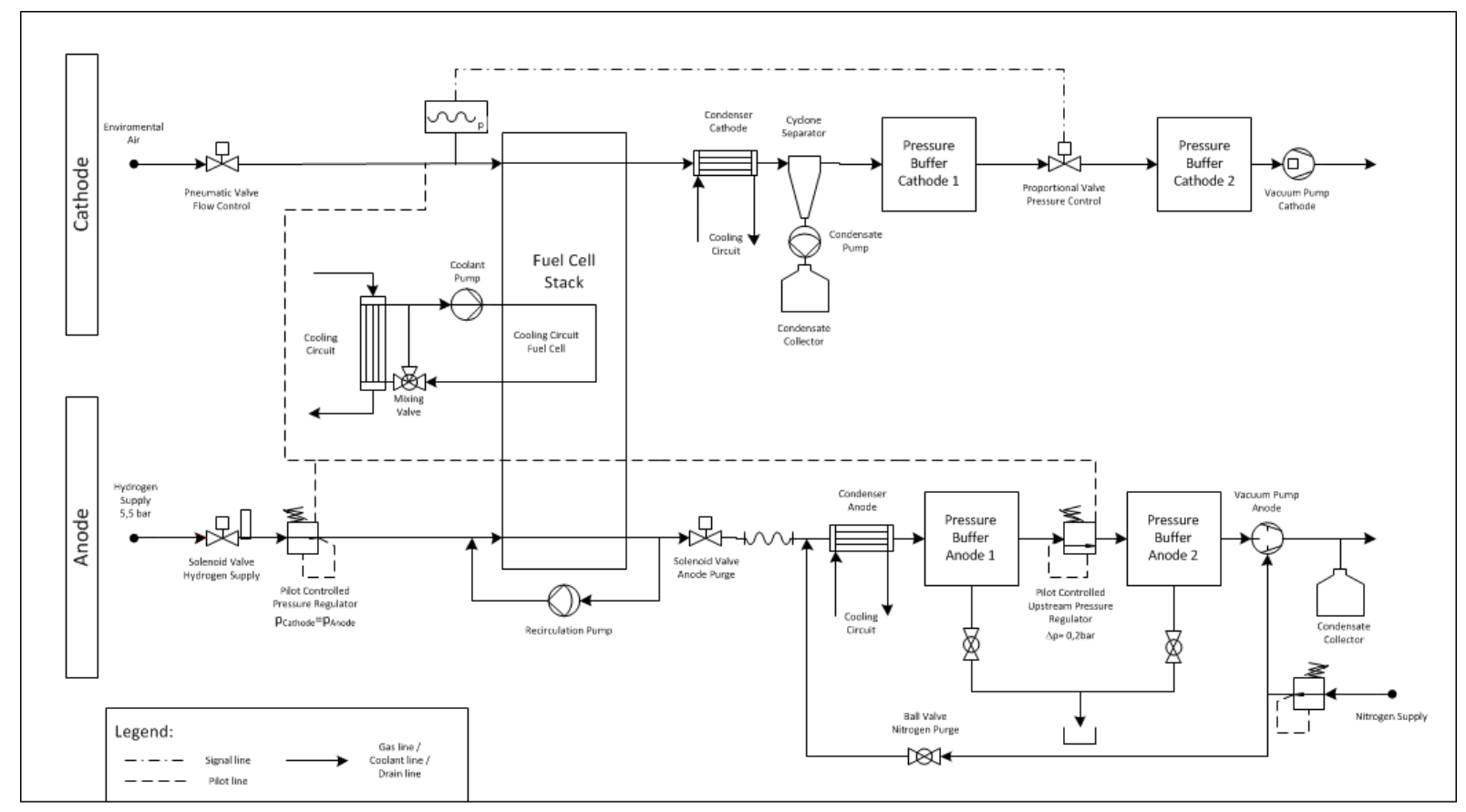

Figure 4: Principle process scheme of the low-pressure test facility for the PEMFC device under test [8]. 


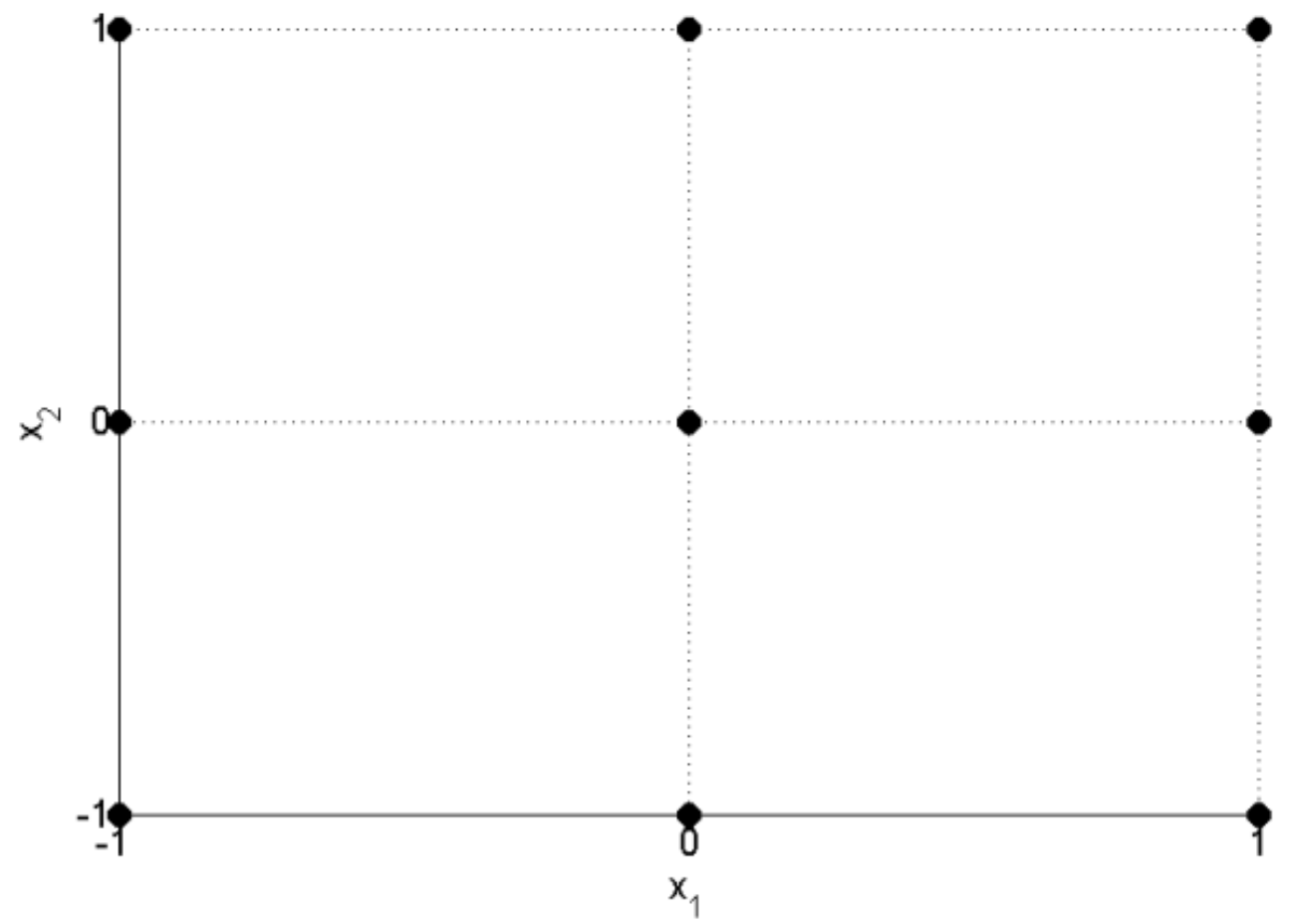

Figure 5: Candidate set of nine experimental runs for two variables $X_{1}, X_{2}$ each investigated at levels $-1,0,1$ (full-factorial design).



Figure 6: Candidate set of three of nine experimental runs for two variables $X_{1}, X_{2}$ each investigated at levels $-1,0,1(D$-optimal design with $\operatorname{det}(J)=4)$. 


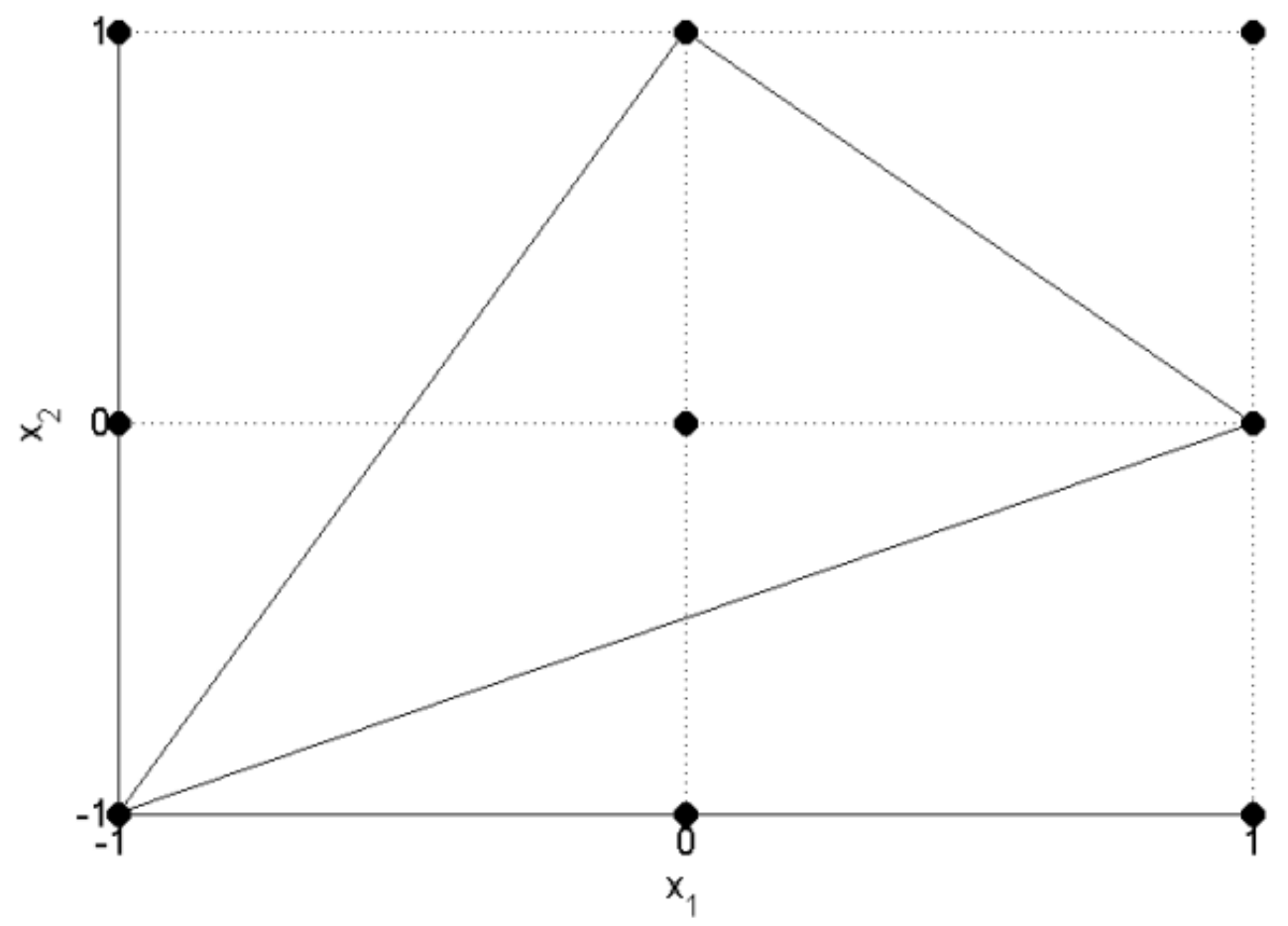

Figure 7: Candidate set of three of nine experimental runs for two variables $X_{1}, X_{2}$ each investigated at levels $-1,0,1(D$-optimal $\operatorname{design}$ with $\operatorname{det}(J)=9)$.

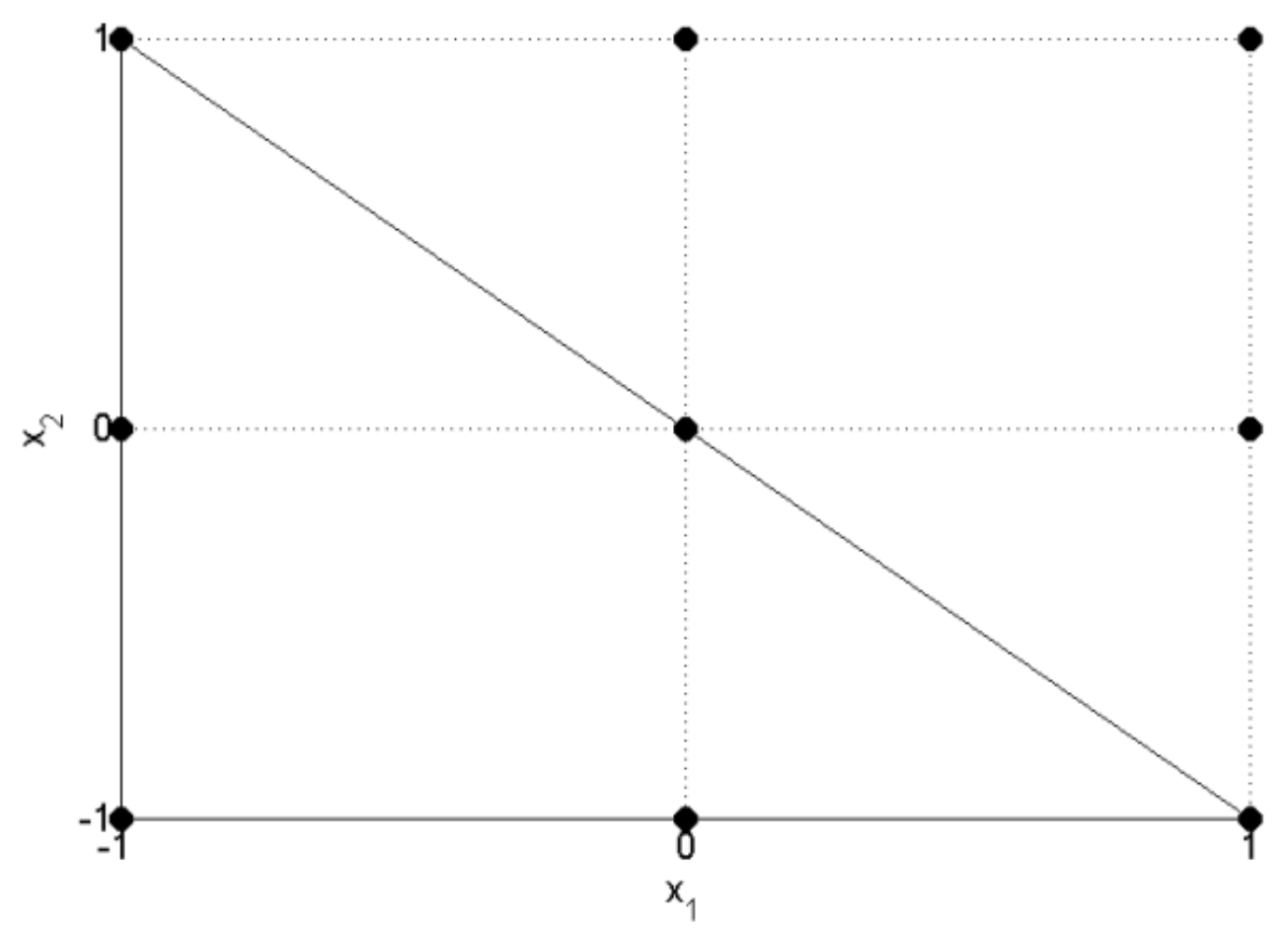

Figure 8: Candidate set of three of nine experimental runs for two variables $X_{1}, X_{2}$ each investigated at levels $-1,0,1(D$-optimal design with $\operatorname{det}(J)=16)$. 


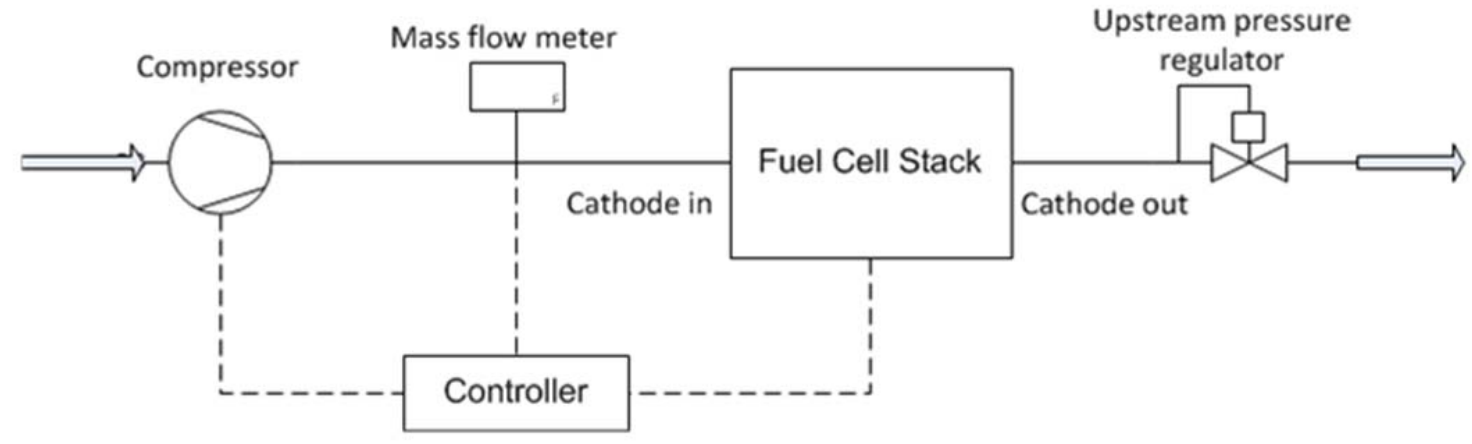

Figure 9: Principal configuration of the supercharged PEMFC operation.


Figure 10: Characteristic maps of lateral compressor Gardner Denver 2BH7610-0AH16-8. 


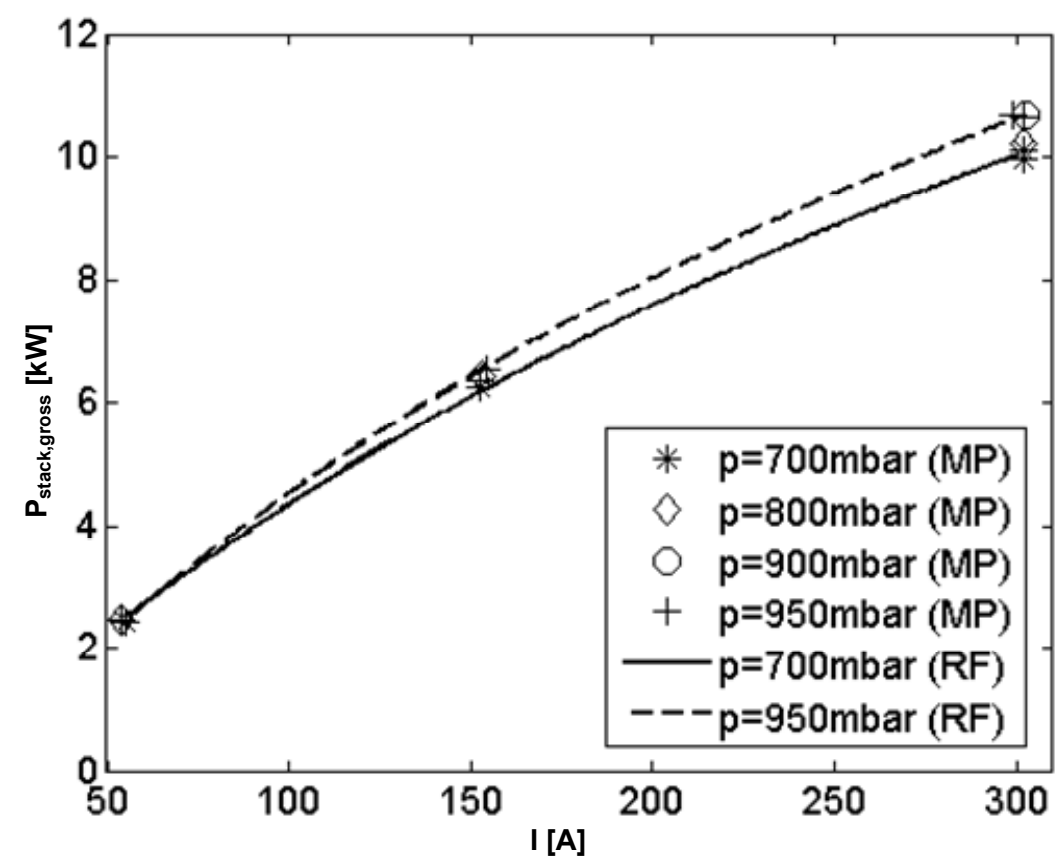

Figure 11: Pressure-dependent stack gross power $P_{\text {stack,gross }}$ of low-pressure PEMFC operation under varying load requirements $I$ (fixed operating parameters: $\lambda=2.1, t=45^{\circ} \mathrm{C}$ ).



Figure 12: Pressure-dependent average voltage efficiency $\eta_{U}$ of low-pressure PEMFC operation under varying load requirements $I$ (fixed operating parameters: $\lambda=2.1, t=45^{\circ} \mathrm{C}$ ). 


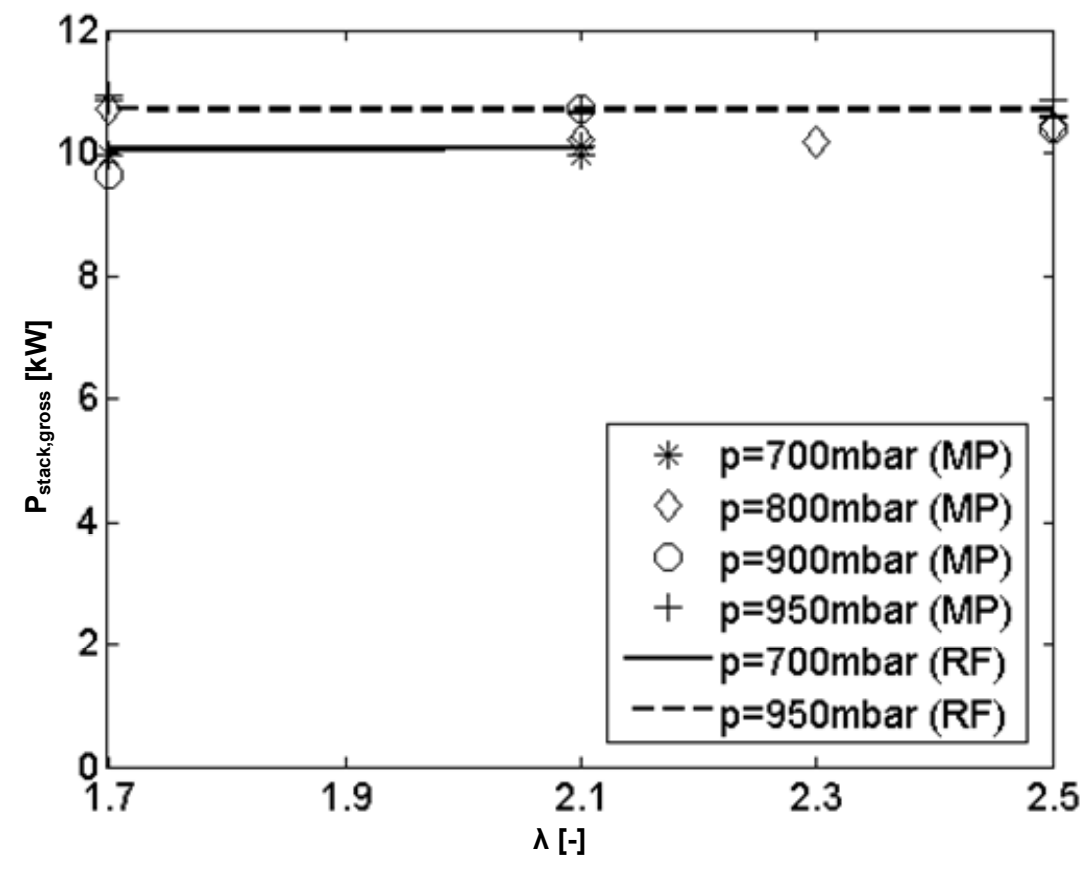

Figure 13: Pressure-dependent stack gross power $P_{\text {stack,gross }}$ of low-pressure PEMFC operation under varying cathode stoichiometric ratios $\lambda$ (fixed operating parameters: $I=300 A, t=45^{\circ} \mathrm{C}$ ).

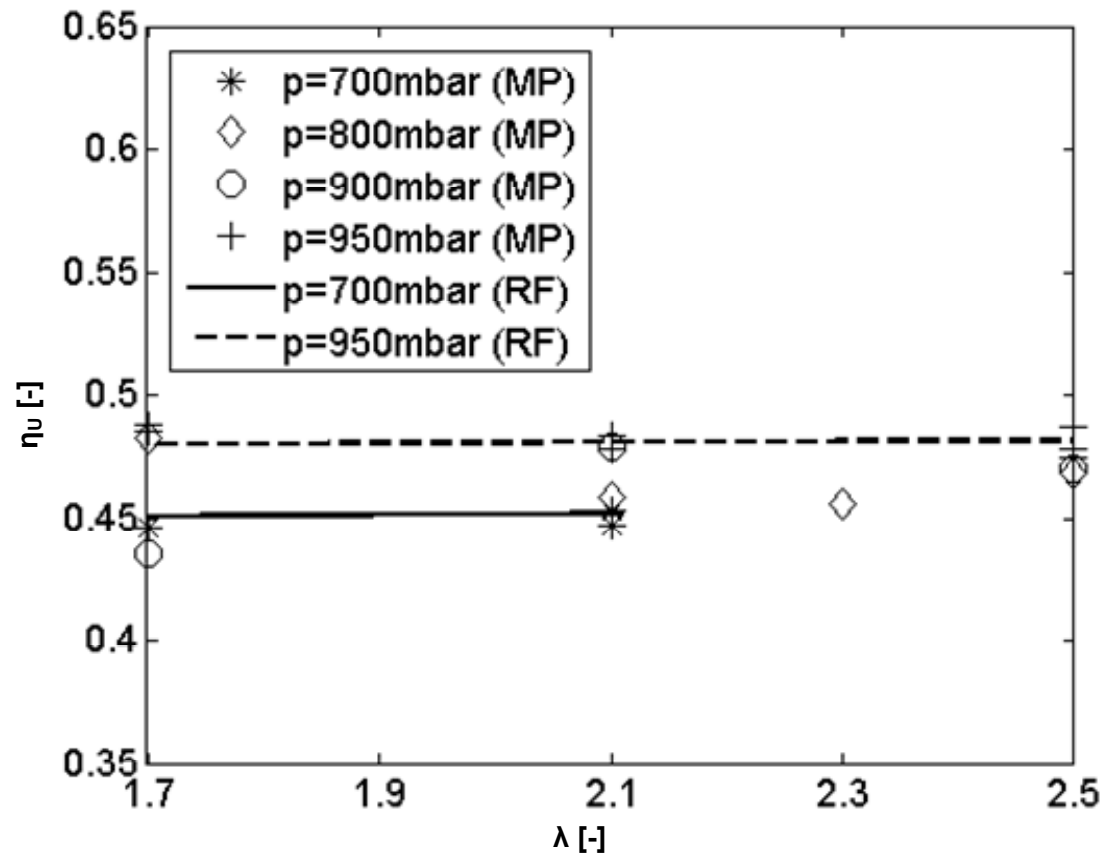

Figure 14: Pressure-dependent average voltage efficiency $\eta_{U}$ of low-pressure PEMFC operation under varying cathode stoichiometric ratios $\lambda$ (fixed operating parameters: $I=300 \mathrm{~A}, t=45^{\circ} \mathrm{C}$ ). 


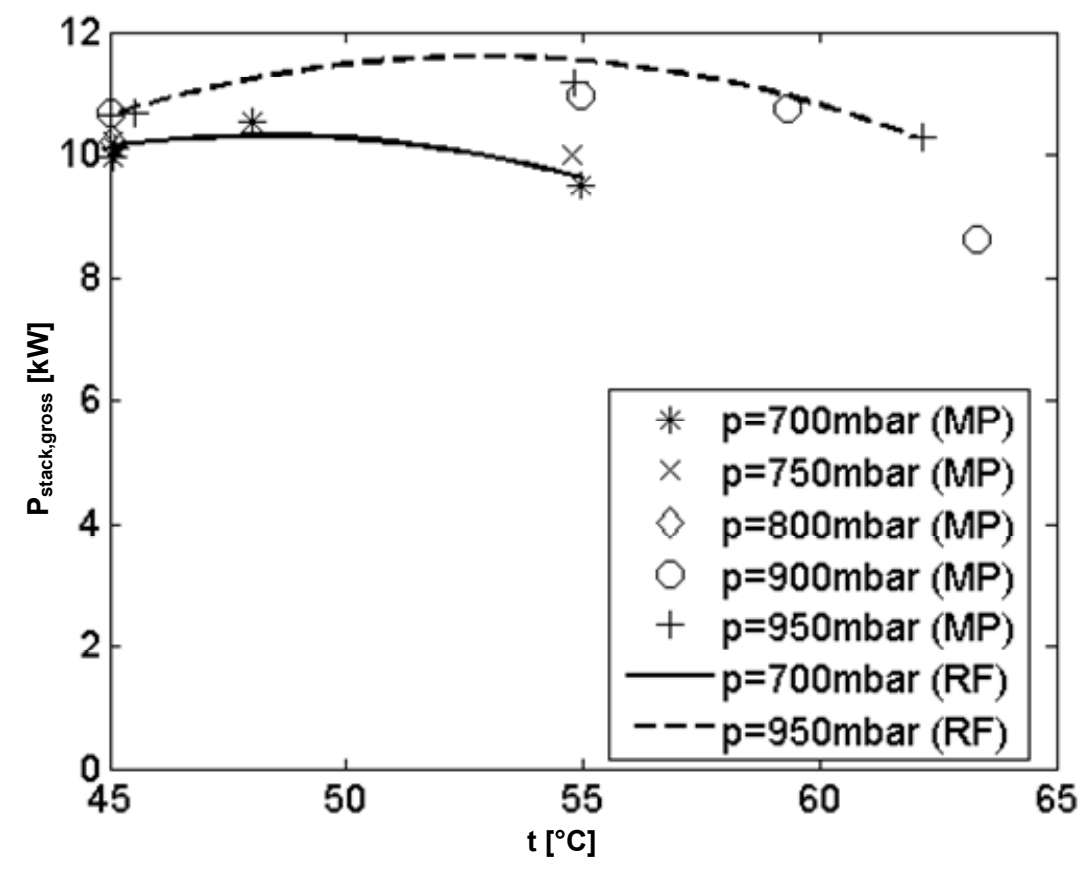

Figure 15: Pressure-dependent stack gross power $P_{\text {stack, gross }}$ of low-pressure PEMFC operation under varying cooling temperatures $t$ (fixed operating parameters: $I=300 A, \lambda=2.1$ ).

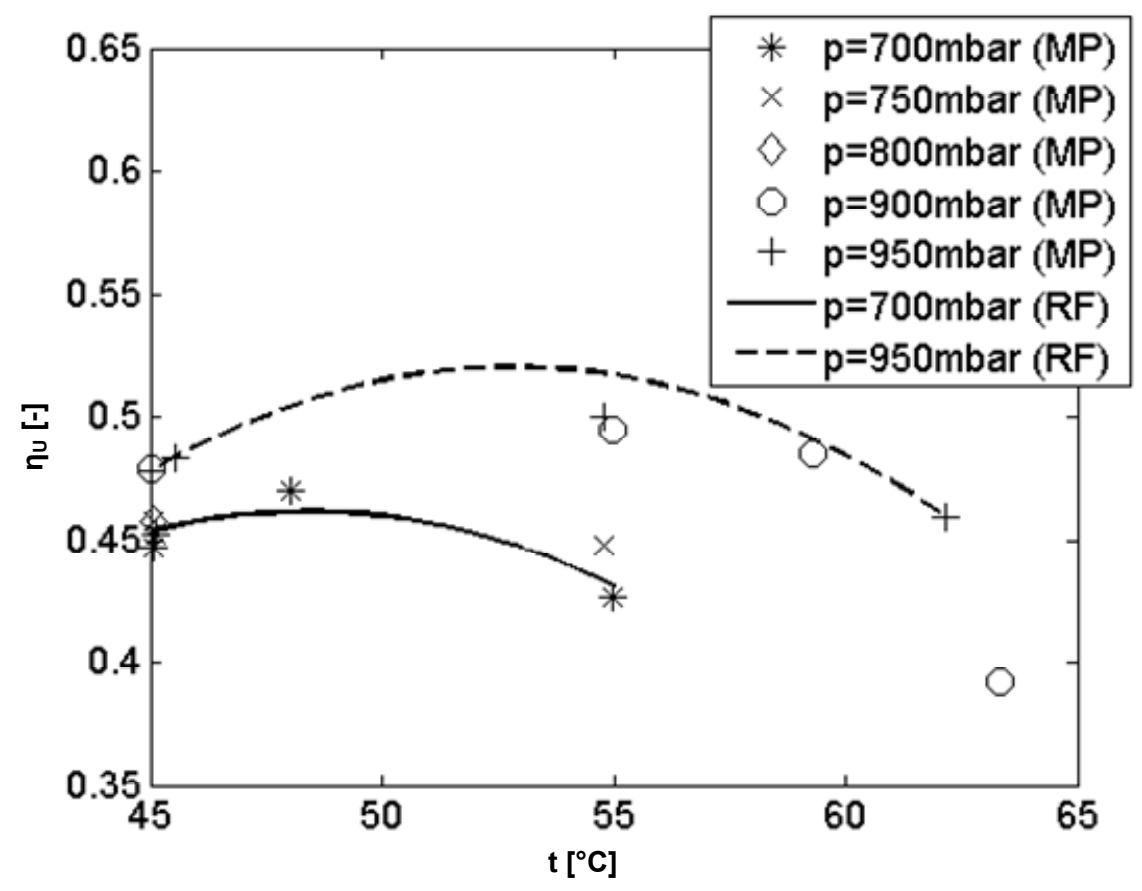

Figure 16: Pressure-dependent average voltage efficiency $\eta_{U}$ of low-pressure PEMFC operation under varying cooling temperatures $t$ (fixed operating parameters: $I=300 A, \lambda=2.1$ ). 




Figure 17: Pressure-dependent system net power $P_{\text {system,net }}$ of supercharged PEMFC operation under varying load requirements $I$ (fixed operating parameters: $\lambda=2.1, t=45^{\circ} \mathrm{C}$ ).

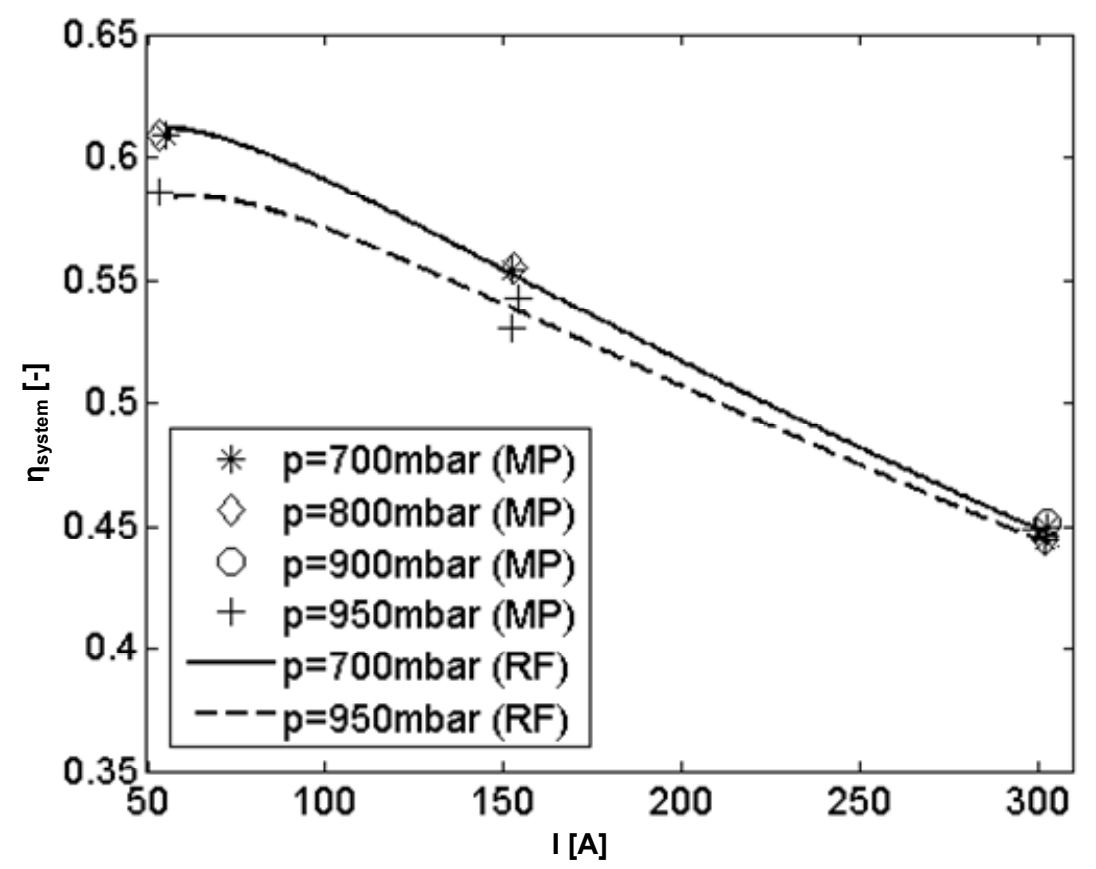

Figure 18: Pressure-dependent total system efficiency $\eta_{\text {system }}$ of supercharged PEMFC operation under varying load requirements $I$ (fixed operating parameters: $\lambda=2.1, t=45^{\circ} \mathrm{C}$ ). 




Figure 19: Pressure-dependent system net power $P_{\text {system,net }}$ of supercharged PEMFC operation under varying cathode stoichiometric ratios $\lambda$ (fixed operating parameters: $I=300 A, t=45^{\circ} \mathrm{C}$ ).

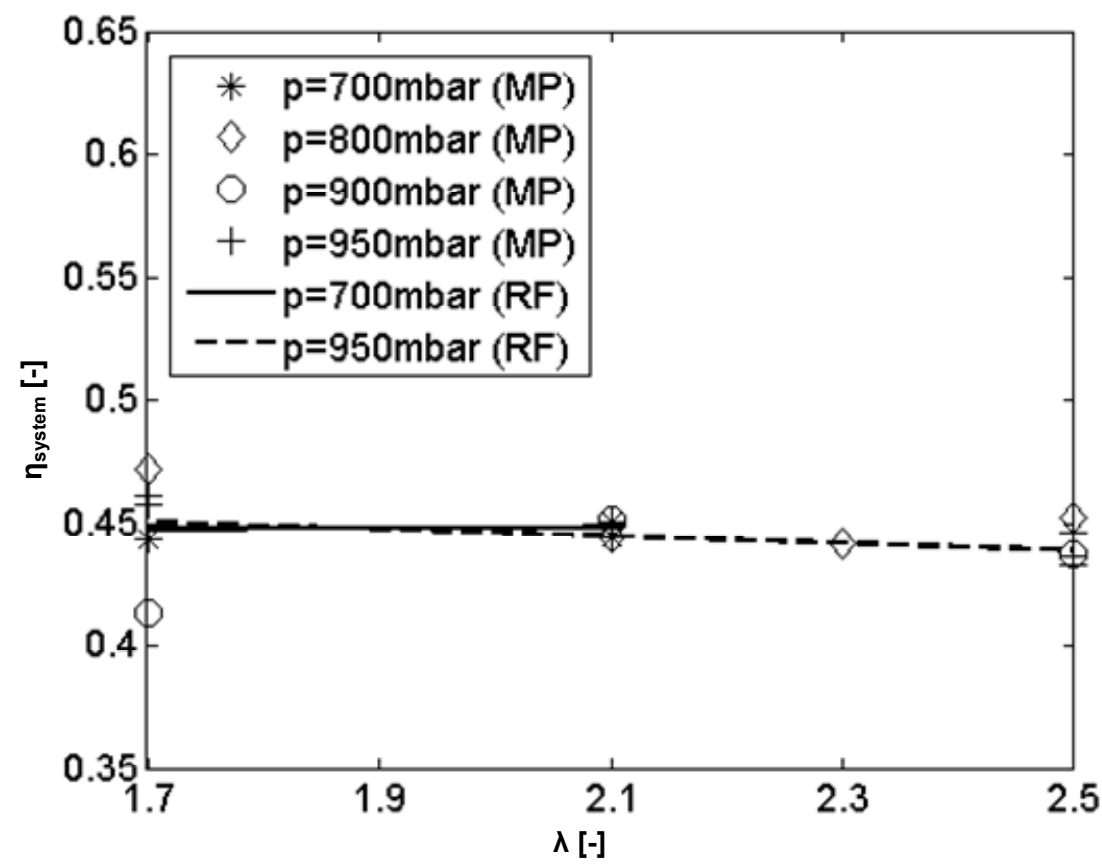

Figure 20: Pressure-dependent total system efficiency $\eta_{\text {system }}$ of supercharged PEMFC operation under varying cathode stoichiometric ratios $\lambda$ (fixed operating parameters: $I=300 \mathrm{~A}, t=45^{\circ} \mathrm{C}$ ). 


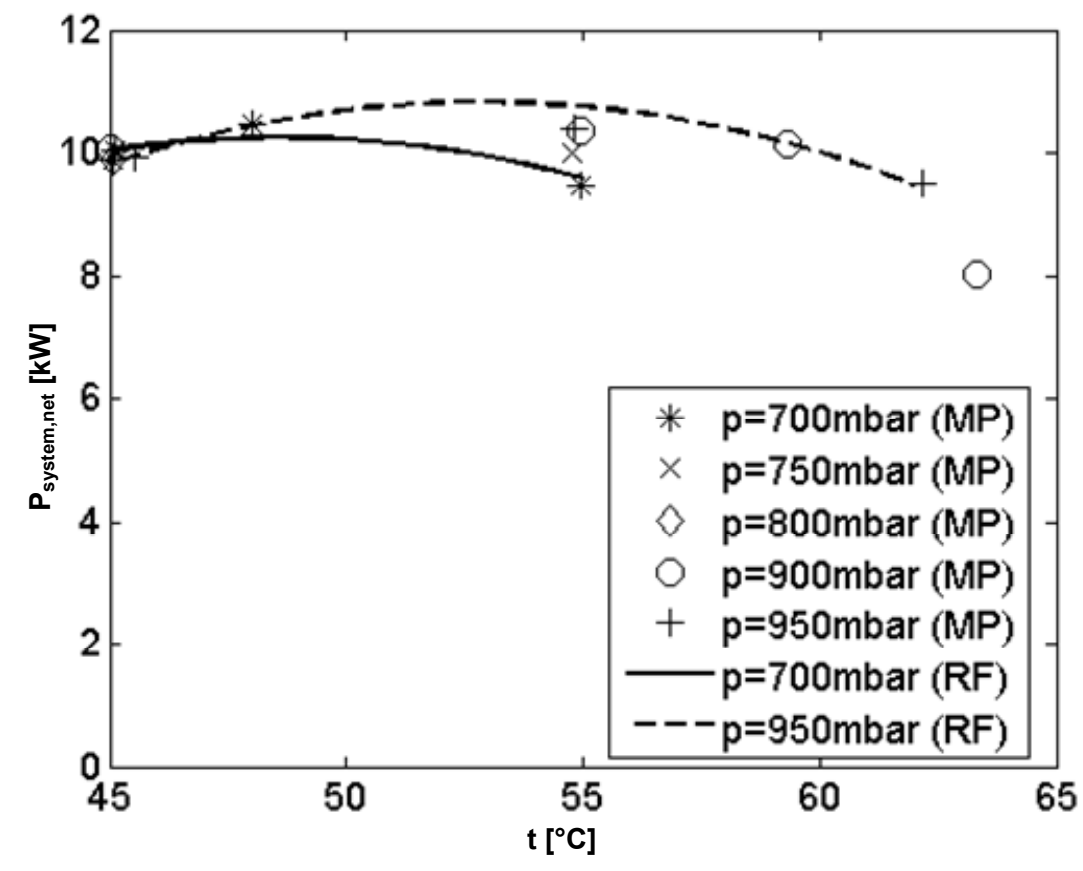

Figure 21: Pressure-dependent system net power $P_{\text {system,net }}$ of supercharged PEMFC operation under varying cooling temperatures $t$ (fixed operating parameters: $I=300 A, \lambda=2.1$ ).

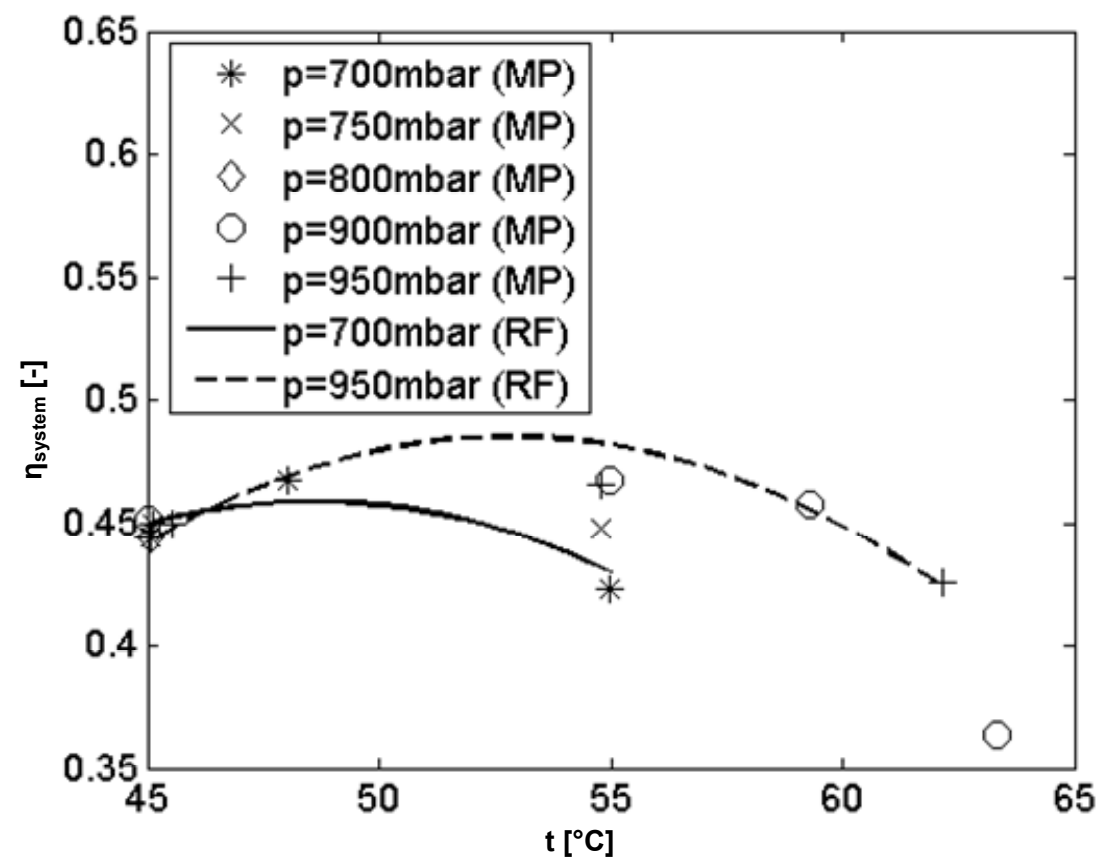

Figure 22: Pressure-dependent total system efficiency $\eta_{\text {system }}$ of supercharged PEMFC operation under varying cooling temperatures $t$ (fixed operating parameters: $I=300 A, \lambda=2.1$ ). 




Figure 23: Sensitivity analysis of stack gross power $P_{\text {stack,gross }}$ of low-pressure PEMFC operation with respect to operating parameters $I, \lambda$ and $t$ at experimental reference point RP.

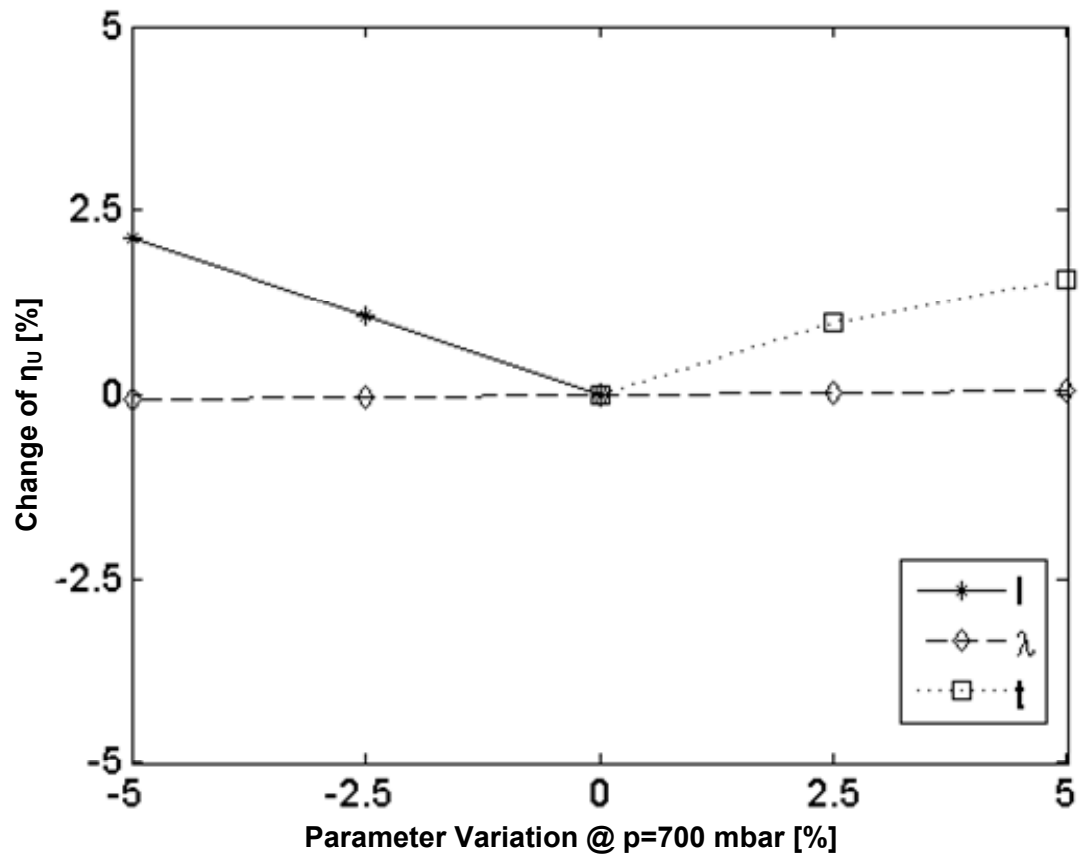

Figure 24: Sensitivity analysis of average voltage efficiency $\eta_{U}$ of low-pressure PEMFC operation with respect to operating parameters $I, \lambda$ and $t$ at experimental reference point RP. 


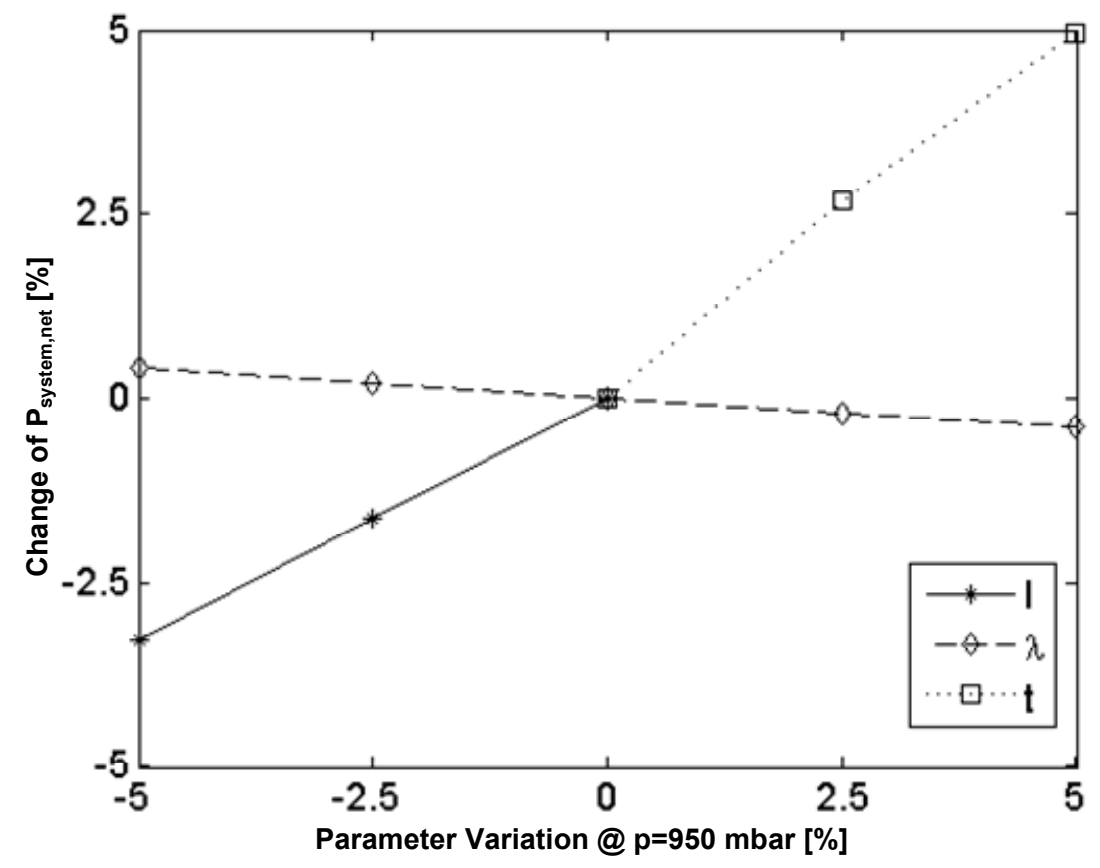

Figure 25: Sensitivity analysis of stack gross power $P_{\text {system,net }}$ of supercharged PEMFC operation with respect to operating parameters $I, \lambda$ and $t$ at experimental reference point RP.



Figure 26: Sensitivity analysis of total system efficiency $\eta_{\text {system }}$ of supercharged PEMFC operation with respect to operating parameters $I, \lambda$ and $t$ at experimental reference point RP. 


\section{Tables}

Table 1: Basic specifications of Hydrogenics' HyPM-XR 12 fuel cell module [5].

Number of Cells
Active Surface Area
Net Rated Electrical Power
Operating Current Range
Operating Voltage Range
Peak Electrical Efficiency
Heat Rejection
Catalyst Platinum Loading

Description

Value

60

$496 \mathrm{~cm}^{2}$

$12 \mathrm{~kW}$

$0 A-350 A$

$35 \mathrm{~V}-58 \mathrm{~V}$

$53 \%$

$<15 k W$

$0.3 \mathrm{mg} / \mathrm{cm}^{2}$

Table 2: Interval and step size of PEMFC operating parameters for experimental investigation.

\begin{tabular}{lccccc}
\multicolumn{1}{c}{ Operating Parameter } & \multicolumn{5}{c}{ Parameter Values } \\
\hline Operating Pressure $p[\mathrm{mbar}]$ & 600 & 700 & 800 & 900 & 950 \\
Cooling Temperature $t\left[{ }^{\circ} \mathrm{C}\right]$ & 45 & 50 & 55 & 60 & 65 \\
Cathode Stoichiometry $\lambda[-]$ & 1.7 & 1.9 & 2.1 & 2.3 & 2.5 \\
Load Requirement $I[A]$ & 50 & 150 & 250 & 300 & 350
\end{tabular}

Table 3: Numerical regression coefficients for low-pressure PEMFC operation.

\begin{tabular}{ccccccc}
$\begin{array}{c}\text { Dependent } \\
\text { Variables }\end{array}$ & \multicolumn{3}{c}{$\eta_{U}$} & \multicolumn{3}{c}{$P_{\text {stack,gross }}$} \\
\hline $\begin{array}{c}\text { Independent } \\
\text { Variables }\end{array}$ & $(I, p)$ & $(\lambda, p)$ & $(t, p)$ & $(I, p)$ & $(\lambda, p)$ & $(t, p)$ \\
\hline$a_{0}$ & 0.57918606 & 0.45898981 & 0.45697735 & 5.62200172 & 10.2101628 & 10.1618654 \\
$a_{1}$ & -0.09249523 & 0.00085604 & -0.07314305 & 4.50183093 & 0.02511624 & -1.66430927 \\
$a_{2}$ & 0.01576906 & 0.01816613 & 0.05976342 & 0.25133666 & 0.35573547 & 1.29852792 \\
$a_{3}$ & 0.00971601 & $-6.64 E-05$ & 0.042779 & 0.25770739 & -0.02927559 & 0.9925897 \\
$a_{4}$ & -0.05228755 & 0.00350791 & -0.06931556 & 1.17881693 & 0.12538622 & -1.57905404 \\
$a_{5}$ & -0.008124 & -0.00021241 & 0.00017692 & -0.08942156 & 0.01507923 & 0.07289244
\end{tabular}

Table 4: Numerical regression coefficients for supercharged PEMFC operation.

\begin{tabular}{ccccccc}
$\begin{array}{c}\text { Dependent } \\
\text { variables }\end{array}$ & \multicolumn{3}{c}{$\eta_{U}$} & \multicolumn{3}{c}{$P_{\text {stack,gross }}$} \\
\hline $\begin{array}{c}\text { Independent } \\
\text { variables }\end{array}$ & $(I, p)$ & $(\lambda, p)$ & $(t, p)$ & $(I, p)$ & $(\lambda, p)$ & $(t, p)$ \\
\hline$a_{0}$ & 0.56743408 & 0.44743298 & 0.44730643 & 5.53263663 & 9.95377545 & 9.94855683 \\
$a_{1}$ & -0.09261461 & -0.00138875 & -0.07213819 & 4.35882485 & -0.02546584 & -1.63891163 \\
$a_{2}$ & -0.00436349 & -0.0021805 & 0.03837369 & 0.00115241 & -0.0952967 & 0.82225828 \\
$a_{3}$ & 0.00959877 & -0.00440195 & 0.04144095 & 0.02373742 & -0.12372422 & 0.95913514 \\
$a_{4}$ & -0.05247955 & -0.00059256 & -0.07034114 & 1.07177818 & 0.03204539 & -1.59945844 \\
$a_{5}$ & -0.01174462 & -0.00013887 & -0.00408596 & -0.12506706 & 0.0155106 & -0.02581889
\end{tabular}


Table 5: Power demand of external compressor for supercharging PEMFC device under test with varying load requirement.

\begin{tabular}{cccc} 
Load Requirement $[A]$ & Flow Rate $\left[\mathrm{m}^{3} / h\right]$ & $P_{\text {BOP,external }}[W]$ & $\eta_{\text {BOP,external }}[\%]$ \\
\hline 50 & 6.69 & 12 & 99.48 \\
150 & 6.83 & 33 & 99.47 \\
300 & 13.55 & 67 & 99.33
\end{tabular}

Table 6: Power demand of external compressor for supercharging PEMFC device under test with varying cathode stoichiometric ratio.

\begin{tabular}{cccc} 
Stoichiometric Ratio - & Flow Rate $\left[\mathrm{m}^{3} / \mathrm{h}\right]$ & $P_{\text {BOP,external }}[W]$ & $\eta_{\text {BOP,external }}[\%]$ \\
\hline 1.7 & 32.12 & 52.6 & 99.48 \\
2.1 & 39.56 & 64.5 & 99.35
\end{tabular}

Table 7: Power demand of external compressor for supercharging PEMFC device under test with varying cooling temperature.

\begin{tabular}{cccc} 
Cooling Temperature $[t]$ & Flow Rate $\left[\mathrm{m}^{3} / h\right]$ & $P_{\text {BOP,external }}[W]$ & $\eta_{\text {BoP,external }}[\%]$ \\
\hline 45 & 39.55 & 64.5 & 99.35 \\
50 & 39.71 & 64.5 & 99.38 \\
55 & 39.54 & 64.5 & 99.31
\end{tabular}

